\title{
Article
}

\section{The Influence of Culture on the Viewing of Western and East Asian Paintings}

Trawinski, Tobiasz, Zang, Chuanli, Liversedge, Simon Paul, Ge, Yao and Donnelly, Nick

Available at https://clok.uclan.ac.uk/37549/

Trawinski, Tobiasz, Zang, Chuanli orcid iconORCID: 0000-0002-9573-4968,

Liversedge, Simon Paul orcid iconORCID: 0000-0002-8579-8546, Ge, Yao and Donnelly, Nick (2021) The Influence of Culture on the Viewing of Western and East Asian Paintings. Psychology of Aesthetics, Creativity, and the Arts . ISSN 1931-3896

It is advisable to refer to the publisher's version if you intend to cite from the work. http://dx.doi.org/10.1037/aca0000411

For more information about UCLan's research in this area go to http://www.uclan.ac.uk/researchgroups/ and search for < name of research Group $>$.

For information about Research generally at UCLan please go to http://www.uclan.ac.uk/research/

All outputs in CLoK are protected by Intellectual Property Rights law, including Copyright law. Copyright, IPR and Moral Rights for the works on this site are retained by the individual authors and/or other copyright owners. Terms and conditions for use of this material are defined in the policies page.

\section{CLoK}

Central Lancashire online Knowledge www.clok.uclan.ac.uk

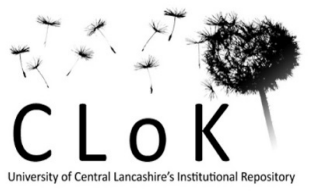


Running head: CROSS-CULTURAL DIFFRENCES IN VIEWING OF PAINTINGS

The Influence of Culture on the Viewing of Western and East Asian Paintings

Tobiasz Trawinski ${ }^{1}$, Chuanli Zang ${ }^{2,3}$, Simon P. Liversedge ${ }^{3}, \mathrm{Yao}^{2}{ }^{2}$, Ying Fu², \& Nick Donnelly ${ }^{4}$

${ }^{1}$ Tobiasz Trawinski, Department of Psychology, Division of Science, New York University Abu Dhabi, United Arabic Emirates

${ }^{2}$ Academy of Psychology and Behaviour, Tianjin Normal University, China

${ }^{3}$ School of Psychology, University of Central Lancashire, United Kingdom

${ }^{4}$ Department of Psychology, Liverpool Hope University, United Kingdom

Contact details:

Tobiasz Trawinski

Department of Psychology, Division of Science

New York University Abu Dhabi

PO Box 129188, Saadiyat Island, Abu Dhabi

UAE

tobiasz.trawinski@nyu.edu 


\begin{abstract}
The influence of British and Chinese culture on the viewing of paintings from Western and East Asian traditions was explored in an old/new discrimination task. Accuracy data were considered alongside signal detection measures of sensitivity and bias. The results showed participant culture and painting tradition interacted but only with respect to response bias and not sensitivity. Eye movements were also recorded during encoding and discrimination. Paintings were split into regions of interest defined by faces, or the theme and context in order to analyse the eye movement data. With respect to the eye movement data, the results showed that a match between participant culture and painting tradition increased the viewing of faces in paintings at the expense of the viewing of other locations, an effect interpreted as a manifestation of the Other Race Effect on the viewing of paintings. There was, however, no evidence of broader influence of culture on the eye movements made to paintings as might be expected if culture influenced the allocation of attention more generally. Taken together, these findings suggest culture influences the viewing of paintings but only in response to challenges to the encoding of faces.
\end{abstract}

Keywords: cross-cultural differences, eye-movements, viewing of paintings, other race effect 
The Influence of Culture on the Viewing of Western and East Asian Paintings

Previous studies investigating the influence of culture on the visual processing of scenes have used photographs or drawings as stimuli. On the basis of such work, Masuda and Nisbett (2001; Nisbett \& Masuda, 2003) argued that culture influences how objects in scenes are attended to, processed and recalled (see also Ji, Peng, \& Nisbett, 2000; Kitayama, Duffy, Kawamura, \& Larsen, 2003; Ko, Lee, Yoon, Kwon, \& Mather, 2011; Masuda, Ellsworth, et al., 2008; Mickley Steinmetz, Sturkie, Rochester, Liu, \& Gutchess, 2018; Yang et al., 2013). They concluded that individuals from collective cultures attend to and represent objects in relation to the context in which they are seen (Boland et al., 2008; Chua et al., 2005; though see Evans et al., 2009; Rayner et al., 2007; Stanley et al., 2013). In contrast, those from more individualistic cultures attend and represent objects relatively independently of their context.

It has also been suggested that cultural differences in scene processing may be reflected in the differences in layout and form of representational paintings from Western and East Asian traditions (Bao et al., 2016; Masuda, Gonzalez, et al., 2008; Miyamoto et al., 2006; Nisbett \& Masuda, 2003; Pöppel, 2018; Ueda \& Komiya, 2012). Representational paintings drawn from Western and East Asian traditions differ. Western representational paintings tend to be constructed using linear perspective and lighting to highlight a single focal point for viewers (Delahaye, 1993). In contrast, East Asian representational paintings tend to use floating perspective (Masuda, Gonzalez, et al., 2008) with a generalised and diffused lighting such that no single focal point for viewing is defined for viewers (Bao et al., 2016; Pöppel, 2018; see Figure 1).

In the present study, we explore if the differences in representational paintings produced in Western and East Asian traditions influence how they are viewed by naïve participants drawn from individualist (British) and collectivist (Chinese) cultures. We do so 
by recording, analysing and comparing eye movements as participants encode examples of Western and East Asian paintings for later recall in an old/new recognition task.

Comparing eye movements across different paintings requires defining regions of interest (ROIs) according to some criterion. One possible way of defining ROIs across traditions comes from art history. Art historians (e.g., Gombrich, 1992, p. 122) often refer to the 'theme' of a painting, whereby some aspects of the composition are essential to the definition of the key narrative of the painting (see also Berlyne, 1971, p. 197, 250-252; Locher et al., 2007). For instance, Arnheim states that: "The theme is a formal pattern that indicates what the work is about. It turns the visual pattern into a semantic statement on the human condition." (Arnheim, 1982, p. 153). Furthermore, Arnheim argues: "If there were an instrument to measure the level of intensity perceived at any point in compositional structure, it would register considerable variation in most works of art. To be sure, there are instances in which visual intensity remains remarkably steady throughout a given work. The crowd scenes of Peter Bruegel or the texture paintings of Jackson Pollock offer examples. But in most styles of art, the statement to be conveyed by the work calls for high points, which carry the accents of the theme, as against the connecting tissue of in-between areas." (1982, p.155).

Paintings showing the same theme share similar semantic and visual features and motif (Panofsky, 1987, p. 40 - 41, Figure 1). Paintings of the same motif are often defined with respect to the presence of specific characters. This is true in both Western and East Asian traditions and so we use this idea to define a 'theme' ROI (see Locher et al., 1996, 2015; Nodine et al., 1993; Trawinski et al., 2019 for a similar approach). In the present study we use the idea of 'theme' and context as a way of providing an initial comparison of viewing across participant culture and painting tradition. If participants from collectivist cultures are more likely to look at the context then the theme than those from individualistic cultures then this should be evident in the contrast of Chinese and British participants. While 
paintings might not be viewed in the same way as other visual stimuli (Cavanagh, 2005;

Graham \& Redies, 2010; Hayn-Leichsenring et al., 2013; Melcher \& Cavanagh, 2011), if an influence of culture is present such an effect should be general and hold when viewing paintings in general. 

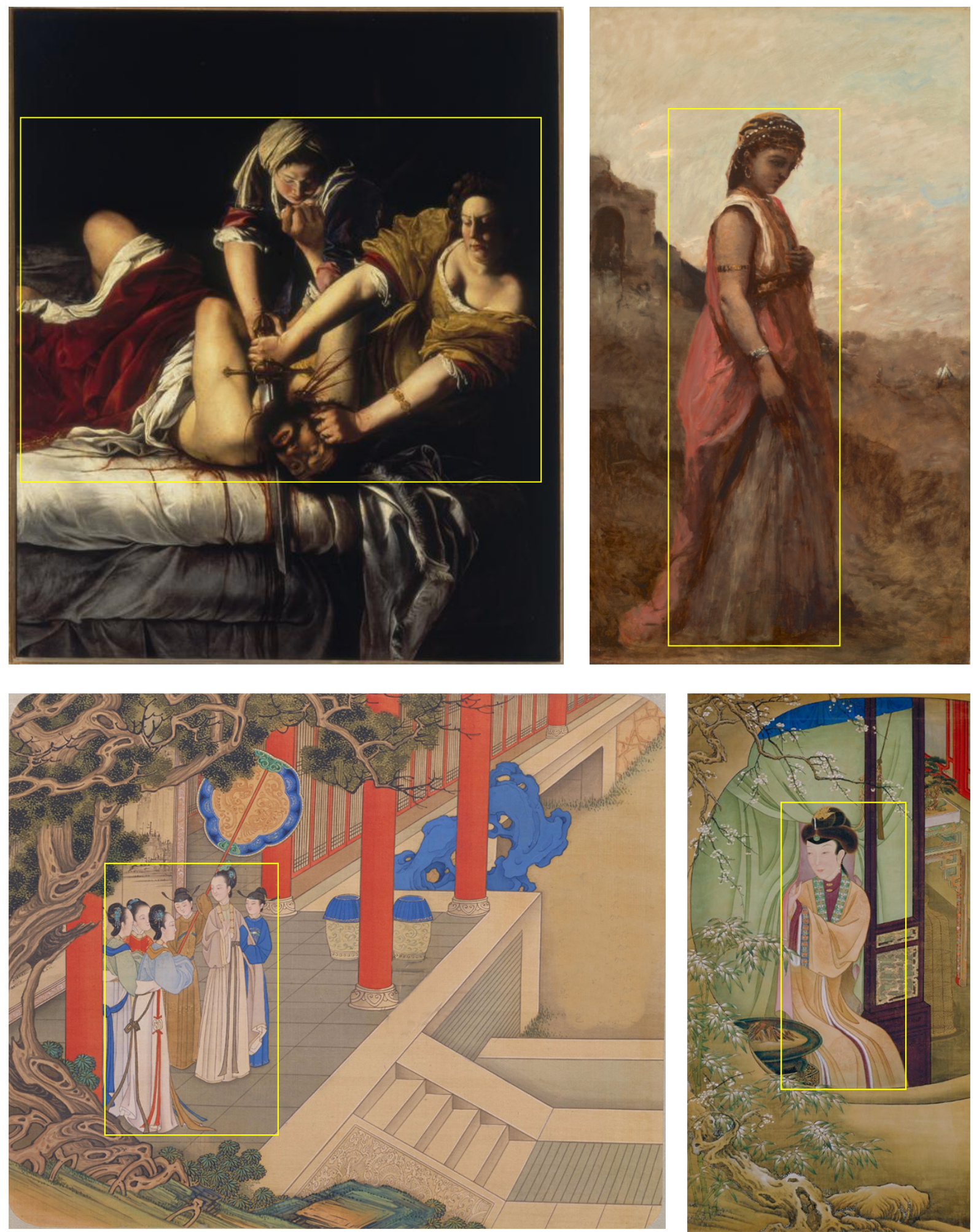

Figure 1. The top panel shows examples of motif of Judith: Gentileschi Artemisia, Judith and

Holofernes (c. 1620); Jean-Baptiste Camille Corot, Judith (c. 1872). The bottom panel shows examples of motif of Nobel Woman: Jiao Bingzhen, Picking Rattan to Make Clothes for 
Parents (Qing dynasty); unknow, Watching Snow Next to Hearth (Qing dynasty). Yellow rectangles show theme ROI.

Appreciation of the idea of theme and context requires knowledge of the history of art and, as such, may be of questionable value in making predictions about the viewing behaviour of naïve spectators. Previous eye movement studies of where participants explored paintings have shown that fixations to faces often dominate much spectatorship of representational paintings by naïve viewers (e.g., Harland et al., 2014; Massaro et al., 2012; Savazzi et al., 2014; Trawinski et al., 2019). It may be that naïve spectators are focused on exploring faces when viewing paintings where they are present. Moreover, the role that faces play in naïve spectators' viewing of paintings is of particular interest with respect to considering how culture might affect spectatorship. The experimental literature on face perception reveals culture to have a marked effect on the identification of faces (e.g., Meissner \& Brigham, 2001), as well as the speed of attentional capture (Masuda, Ellsworth, et al., 2008) and sensitivity to changes made to faces presented in positive, negative or neutral contexts (Ko et al., 2011). These findings sit under the heading of the Other Race Effect (ORE). There is an extensive literature on the ORE in face perception but we limit our discussion here to studies where eye movement measures have been taken. Goldinger et al., (2009) explored this in a study of recognition memory for faces presented individually in an old/new recognition task. They demonstrated that other race faces are subject to fewer but longer fixations than are same race faces when encoding faces into memory. Furthermore, they demonstrated that the influence of race on eye movements to faces became more marked as the encoding session progressed. The finding of an effect of time through the encoding session was explained in terms of the diminishing effort participants were willing to expend in the encoding of other race faces over the time course across trials. If these data are relevant 
to understanding the viewing of representational paintings then culture will influence the extent of looking at faces. Specifically, on average, where participant culture and painting tradition match then faces will be viewed more than when there is a mismatch.

Beyond the hypothesis of a specific effect in relation to the viewing of faces, the broader consequences of the influence that the ORE might play in the viewing of paintings remains unclear. In particular, is viewing shifted away from faces to other areas of the theme and context, or is it simply truncated when there is a mismatch relative to a match between participant culture and painting tradition? This question is explored in the present study.

The hypothesis of a match (or mismatch) between participant culture and painting tradition leading to a difference in the viewing of faces can be extended. Discrimination in an old/new discrimination task like that used in the present study amounts to making a decision of 'have I seen this before?'. Targets seen at encoding can be positively identified whereas foils (i.e., those not seen at encoding) cannot be. Decisions of this type are subject to uncertainty about when enough visual information has been sampled. For example, uncertainty about the decision making in relation to target absence is known to increase eye movements relative those made when decided a target is present in visual search tasks (e.g., Chun \& Wolfe, 1996). The likely increased number of eye movements on foil than target trials may lead to exaggerated effects on foil relative to target trials. The increased number of eye movements to foils than targets provides a larger sample size of eye movements from which to test for differences. Therefore, if culture influences the viewing of paintings at discrimination then these effects will be seen most clearly on foil than target trials.

In sum, in the present study, participants viewed Western and East Asian paintings as they sought to encode them into memory in order to discriminate those seen at encoding (targets) from those not seen at encoding (foils). Discrimination accuracy was measured to ensure participants were attending to the task, and eye movements were measured 
throughout. Three hypotheses have been tested. First, when looking at paintings Chinese participants will look more to the context, and less to the theme, than will British participants. Second, a mismatch relative to a match between a participant's culture and the tradition from which a painting is drawn will influence eye movements made at encoding and discrimination by virtue of the other race effect on viewing of paintings. Third, any influence of culture on the viewing of themes, context or faces at discrimination will be most striking on trials when foils rather than targets are presented.

\section{Method}

\section{Participants}

Participants were 32 Chinese (13 males and 19 females; $M=22.5, S D=2.83$ ) and 28 British (4 males and 24 females; $M=21, S D=4.38$ ) undergraduate students from the Tianjin Normal University (PRC), University of Southampton (UK), and Liverpool Hope University (UK). An opportunity sample was recruited through an online survey advertising the studies. Participants received course credits or payment (£12) to compensate for their time.

Participants were also compared on a set of individual difference measures (see the Procedure section for details in relation to the collection of these data). British and Chinese participant groups did not differ on the Attention Network Task $(p s>.187)$ on most of the scales apart from executive score $(t(58)=-2.08, p=.043$; see Table 1). British participants had higher executive attention scores than Chinese participants. In contrast, Chinese participants had a higher capacity on visuospatial working memory capacity $(t(58)=2.25, p$ $=.028 ; M=63.75, S D=14.06 ; M=54.25, S D=18.6$; respectively). Finally, British and Chinese participants did not differ on verbal working memory capacity $(t(58)=.16, p=$ $.253)$. 
Table 1

The results of battery of cognitive tests used to estimate the individual differences between British and Chinese participants.

\begin{tabular}{ll}
\multicolumn{2}{l}{ Chinese } \\
\hline$M \quad S D$
\end{tabular}

$\begin{array}{lllll}\text { 3-Back: Spatial } & 64.70 & 14.87 & 54.25 & 18.60 \\ \text { 3-Back: Verbal } & 68.46 & 14.94 & 62.71 & 18.05 \\ \text { ANT: EXEC } & 69.60 & 24.83 & 85.98 & 34.75 \\ \text { ANT: ORIENT } & 36.24 & 25.95 & 46.43 & 32.43 \\ \text { ANT: ALERT } & 24.03 & 27.79 & 28.02 & 36.84\end{array}$

Note. $\mathrm{ANT}=$ Attention Network Test EXEC $=$ executive; ORIENT = orienting; $\mathrm{ALERT}=$ alerting.

All participants reported having little knowledge of art. In an attempt to confirm participants were naïve to art, they completed a test of art knowledge. The questionnaire was translated to English and Chinese from the original German version of an art knowledge questionnaire (Jakesch \& Leder, 2009; Trawinski et al., 2019). One inevitable limitation is that the questionnaire explores knowledge of Western art. We are not aware of an equivalent test of knowledge of East Asian art. Participant knowledge about art tended to be low (Chinese: $M=1.94$ [out of 48]; $S D=1.86 ; M d n=1$; range = $0-8$; British: $M=9.19 ; S D=$ 6.20; $M d n=7 ;$ range $=0$ - 25). The participants were, therefore, classified as naïve.

The groups of Chinese and British participants were each pseudo-randomly allocated to one of four groups. Groups A (16 participants: Chinese) and B (14 participants: British) viewed Western paintings, and Groups C (16 participants: Chinese) and D (14 participants: British) viewed East Asian paintings. 


\section{Apparatus}

Stimuli were presented on a View-Sonic graphics Series G225f CRT monitor with screen size $40 \mathrm{~cm} \times 30 \mathrm{~cm}$ in a darkened room. Participants were seated at a distance of 70 $\mathrm{cm}$ giving a visual angle of $30.11^{\circ}$ by $23.75^{\circ}$ for the screen. Screen resolution was $1024 \mathrm{x}$ 768 with a refresh rate of $120 \mathrm{~Hz}$. Viewing was binocular, though the only movements of the right eye were recorded using an SR Research Limited Eye-Link 1000 eye tracker operating at $1000 \mathrm{~Hz}$. Head movement was stabilized using a chin and headrest. Participants terminated each presentation by pressing one button on a four-button response box.

\section{Stimuli}

Two sets of 150 high-resolution images of Western and East Asian paintings were downloaded from the Google Image Search. All signatures and descriptions were removed using Adobe Photoshop CS6. The height varied between 3.84 and $26.99 \mathrm{~cm}$ on the screen and giving a visual angle between $6.21^{\circ}$ and $41.56^{\circ}$. Widths varied between 6.69 and $20.11 \mathrm{~cm}$ increasing a visual angle to $14.31^{\circ}$ and $41.32^{\circ}$. Paintings were always presented centrally on the screen against a grey background.

Paintings were drawn from ten motif categories. The set of Western paintings consisted of paintings taken from five motif categories: Three Graces, Judith, Bathers, Odalisque, and Venus. The set of East Asian paintings consisted of five other motifs categories: Palace Children, Rohan, Bodhisattva, Nobel Women and Emperor. Thirty paintings were gathered, in total, for each motif category (see Appendix A and B).

Each painting was split into theme and context ROIs. Given the selection of paintings with respect to specific motifs, we operationalised theme as area(s) of the composition critically relevant to identifying the motif. The determination of theme and context was made, a priori, by one of the authors (TT) and a Professor of Fine Art. The area of a painting beyond 
that contributing to the theme was its context. The area of the theme and context covered, on average, $58 \%$ and $42 \%$ respectively of the Western and $32 \%$ and $68 \%$ respectively of the East Asian paintings. Comparison of the percentage area of themes across tradition of painting showed that the theme occupied a greater area of Western than East Asian paintings $(t(298)=16.88, p<.001)$

\section{Design and Procedure}

The experiment had five stages and all participants completed all stages. In the first stage, participants completed either a test of visuospatial and verbal working memory capacity (3-back task; Shackman et al., 2006) or they completed an art knowledge questionnaire (Jakesch \& Leder, 2009; Trawinski et al., 2019).

In the second stage (the encoding session), participants in Groups A-D were asked to memorise each of one hundred Western (Groups A and B) or East Asian (Groups C and D) paintings for recall in a later discrimination session. Eye movements were recorded during encoding and this required the second stage to begin with a nine-point calibration procedure. The eye tracker was calibrated to less than $0.5^{0}$ error. Once calibration was complete, the presentation of paintings began. Paintings were presented in a randomised order. Each trial began with a fixation cross, presented at the centre of the screen. Once the fixation cross had been fixated for 1 second, a painting was presented and remained on the screen until a key press on the button box indicated that the participant had finished viewing. The inter-trial interval between a button press and the onset of a fixation cross was set to $500 \mathrm{~ms}$.

Stage 3 lasted for 30-minutes during which participants completed whichever of the working memory capacity test or art knowledge questionnaire that they had not completed in the first stage.

In the fourth stage (the discrimination session), fifty 'foil' paintings that were not shown at encoding were presented along with fifty 'target' paintings shown during the 
encoding session in a randomised order. As in the encoding session, eye movements were measured, requiring the fourth stage to begin with a nine-point calibration procedure. The eye tracker was calibrated to less than $0.5^{0}$ error. Once calibration was complete, the presentation of paintings began. The onset of paintings was preceded by a fixation cross, and the offset by a button press. Participants judged whether paintings were targets or foils and responded by pressing one of two buttons on the response box. As at encoding, the inter-trial interval was $500 \mathrm{~ms}$.

In the fifth stage participants completed the Attention Network Test (ANT; Fan et al., 2002). The ANT uses reaction times to determine indices of attentional orienting, alerting and executive control. The test combines a flanker task and a cued reaction time task to measure the efficiency of each aspect of attention. A central arrow is flanked by two pairs of distracter arrows on each trial. Flanker arrows either point in the same direction (congruent condition) or opposite direction (incongruent condition) as the target arrow. Participants were instructed to classify as quickly and accurately as possible whether the central arrow pointed to the left or right. The difference in reaction times between various conditions is used to calculate the range of attention network scores.

\section{Results}

Descriptive statistics for the data gathered in the tests in Stages 1, 3, and 5 of the experimental procedure are reported in the Participants section and were used to compare the two participant groups. Data from stages 2 and 4 were used to test the hypotheses described in the Introduction and are explored in this section.

Data analyses were conducted in R version 3.5.0 (R Core Team, 2016). Data were fitted in (generalised) Linear Mixed-effects Models ((G)LMMs) using the lmer4-package (Bates et al., 2014) and MASS-package (Venables \& Ripley, 2002). We used 'emmeans' 
package (Lenth et al., 2019; version 1.4.5) to create the predicted marginal means, contrasts, and comparisons for fixed factors of models. All pairwise comparisons were corrected using Holm-Bonferroni correction. The random effects were structured for items and participants including slopes for meaningful fixed effects and correlation. The full random structure was trimmed down for those models that did not converge or had a correlation equal to zero or one. The $t / z$-values equal to 1.96 or higher were interpreted as significant (see Baayen et al., 2008).

The results are structured to consider the (a) accuracy in discrimination of paintings from foils (b) eye movements made during the encoding session to theme and context areas, (c) eye movements made at discrimination, and (d) eye movements made to faces, the themes minus faces (remainder of the theme [henceforth $r$-theme]), and contexts during the encoding and discrimination sessions. The random structure for accuracy analyses using GLMM was $(1+$ Test Item $\mid$ Subject $)+(1 \mid$ Stimuli $)$. The random structure for the eye movement measures for the LMM, for both normalised log-transformed number of fixations and for logtransformed fixation duration, was (1+ROI | Subject $)+(1+$ ROI $\mid$ Stimuli $)$ and for logtransformed total fixation duration $(1+\mathrm{ROI} \mid$ Subject $)+(1 \mid$ Stimuli $)$ in the encoding session when theme and context were considered. In the discrimination session the random structure for the LMM for normalised log-transformed number of fixations was $(1+\mathrm{ROI} \mid$ Subject $)+(1 \mid$ Stimuli) and for log-transformed fixation duration and for log-transformed total fixation duration was $(1+\mathrm{ROI}+$ Test Item $\mid$ Subject $)+(1 \mid$ Stimuli $)$. The random structure for the LMM for normalised log-transformed number of fixations, log-transformed fixation duration, and log-transformed total fixation duration was $(1 \mid$ Subject $)+(1 \mid$ Stimuli $)$ in encoding when eye movements made to faces were considered. The random structure for the LMM for normalised log-transformed number of fixations, and log-transformed total fixation duration 
was $(1+\mathrm{ROI} \mid$ Subject $)+(1 \mid$ Stimuli $)$, and for log-transformed fixation duration (1 | Subject $)$

$+(1$ Stimuli), in discrimination when eye movements made to faces were considered.

\section{Discrimination Accuracy}

We start the report of data analysis by testing whether participants were able to perform the discrimination task reliably. The analyses are not conducted to test a specific prediction outlined in the Introduction. Nevertheless, it is important to show that participants were engaged with the task in the encoding and discrimination sessions. Only if this is the case does it make sense to explore specific predictions with respect to the eye movement data (Keith Rayner, 2009). First, the accuracy was processed as a binomial dependent variable in a GLMM (Table 2). The fixed factors were Culture (of participants; Chinese versus British), Tradition (of painting; Western versus East Asian), and Test Item (target versus foil), as well as their interaction.

The reference levels were Chinese for Participants, East Asian for Tradition, and foils for Test Item. Second, accuracy data were used to compute sensitivity $(d)$ and bias $(c$; Macmillan \& Creelman, 2004), which were analysed using analysis of variance. Sensitivity and bias were used as dependent variables, and Culture (Chinese versus British) and Tradition (Western versus East Asian) were between subject factors. 
Table 2

Fixed effect estimates from the Generalised Linear Mixed Models for accuracy on Participant, Painting, and Test Item.

\begin{tabular}{rccc}
\hline & \multicolumn{3}{c}{ Accuracy } \\
\cline { 2 - 4 } Intercept & 1.62 & $S E$ & $z$ \\
Culture & 0.70 & 0.23 & $\mathbf{7 . 2 7}$ \\
Tradition & -0.30 & 0.27 & $\mathbf{2 . 6 4}$ \\
Test Item & 0.58 & 0.32 & -0.94 \\
Culture: Tradition & -0.13 & 0.33 & 1.75 \\
Culture: Test Item & -1.42 & 0.39 & -0.34 \\
Tradition: Test Item & -0.72 & 0.39 & $\mathbf{- 3 . 6 0}$ \\
Culture: Tradition: Test Item & 1.45 & 0.47 & -1.53 \\
\end{tabular}

Note. Significant effects are indicated in bold.

With respect to the accuracy, the main effect of culture was significant as were the interactions between Culture and Test Item and the three-way interaction of Culture, Tradition and Test Item were significant (Figure 2). Specifically, Chinese participants discriminated between Western paintings less accurately than East Asian paintings $(b=1.02$, $z=2.72, p=0.01)$. However, this was only the case when the comparison of Western and East Asian paintings was made across target paintings and not foils. British participants did not differ with respect to discrimination between targets and foils for Western and East Asian paintings $(z \mathrm{~s}<1.27)$. The results for accuracy are explored in more detail below using signal detection theory to differentiate between effects of sensitivity (d') and bias (c). 


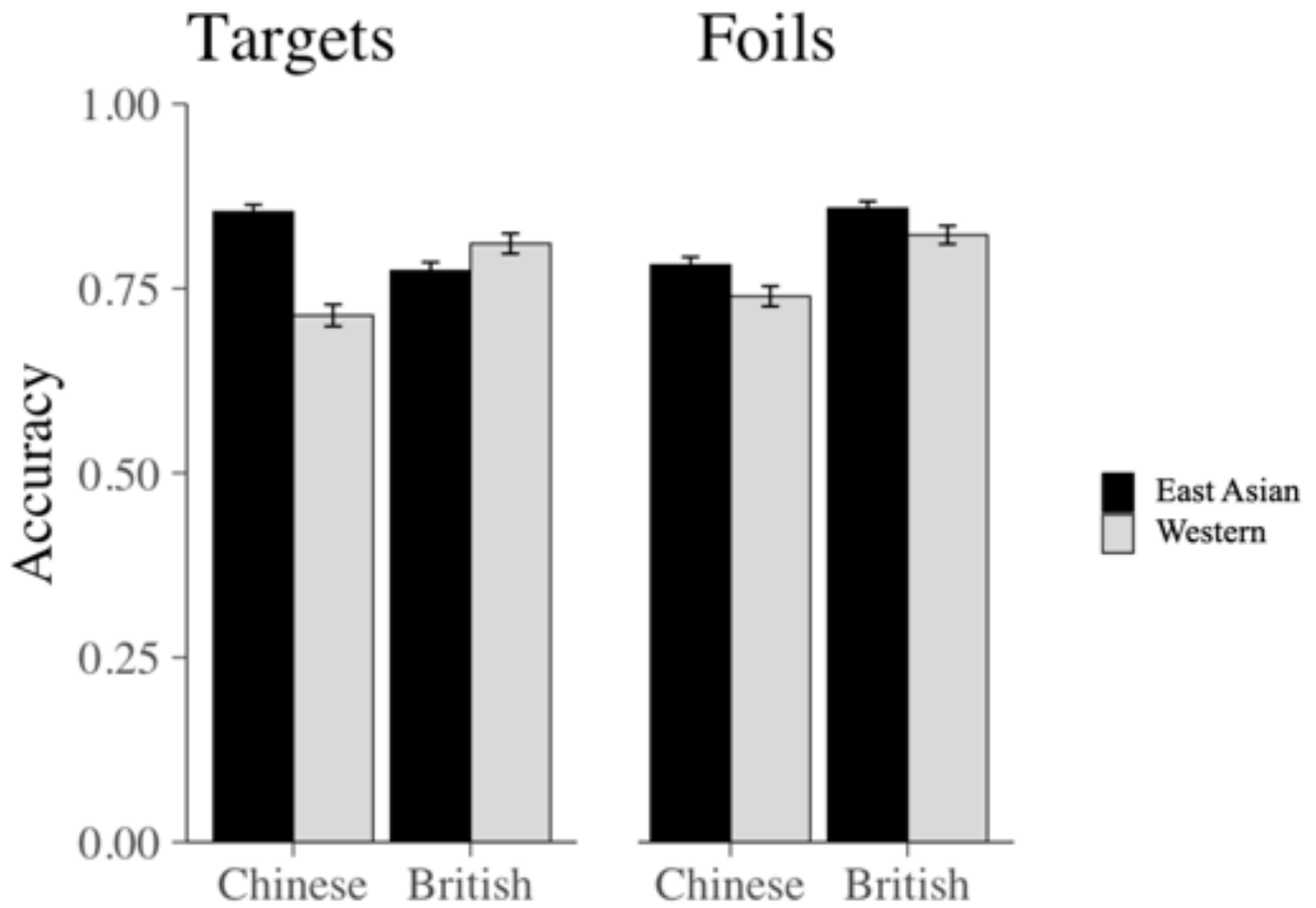

Figure 2 Mean accuracy (with $S E$ ) as a function of Culture, Tradition, and Test Item. and Test. 
Running head: CROSS-CULTURAL DIFFRENCES IN VIEWING OF PAINTINGS

With respect to sensitivity, the main effect of Tradition was significant with sensitivity being higher for East Asian than Western paintings $\left(F(1,56)=4.87, p=0.031, \eta_{p}^{2}\right.$ $=0.08)$. The interaction between Tradition and Culture approached but did not reach significance $\left(F(1,56)=2.72, p=0.105, \eta_{p}{ }^{2}=0.05\right)$. No other main effects reached significance $(F s<2.16)$. In sum, sensitivity was higher to East Asian than Western paintings. With respect to bias, the main effect of Culture $\left(F(1,56)=4.20, p=0.045, \eta_{p}{ }^{2}=\right.$ 0.07), and the interaction between Culture and Tradition was significant $(F(1,56)=8.43, p=$ $\left.0.005, \eta_{p}{ }^{2}=0.13\right)$. British participants were biased to report East Asian paintings as foils. In contrast, Chinese participants were biased to report East Asian paintings as targets (Mdiff $=$ $.56, p=0.003$; Figure 3 ). There was no effect of culture on response bias when discriminating Western paintings $(p s<.179)$. No other main effects reached significance $(F \mathrm{~s}$ $<.01)$.

The main purpose of these analyses was to report that participants were able to perform the task. The discrimination data show that participants found the task challenging but were clearly engaged with it. We did not predict any effect of culture on accuracy, sensitivity, or bias. There was, however, some evidence that discrimination accuracy was increased for the East Asian paintings than for the Western paintings, and this effect was more apparent for Chinese participants. There was also evidence of an influence of culture on decision bias in the discrimination of East Asian paintings. Chinese participants tended to see East Asian paintings shown at discrimination as familiar whereas British participants tended to see them as unfamiliar. We now turn to the analyses of the eye movements made when encoding and discriminating paintings, having demonstrated that participants were able to perform the task reasonably well. 

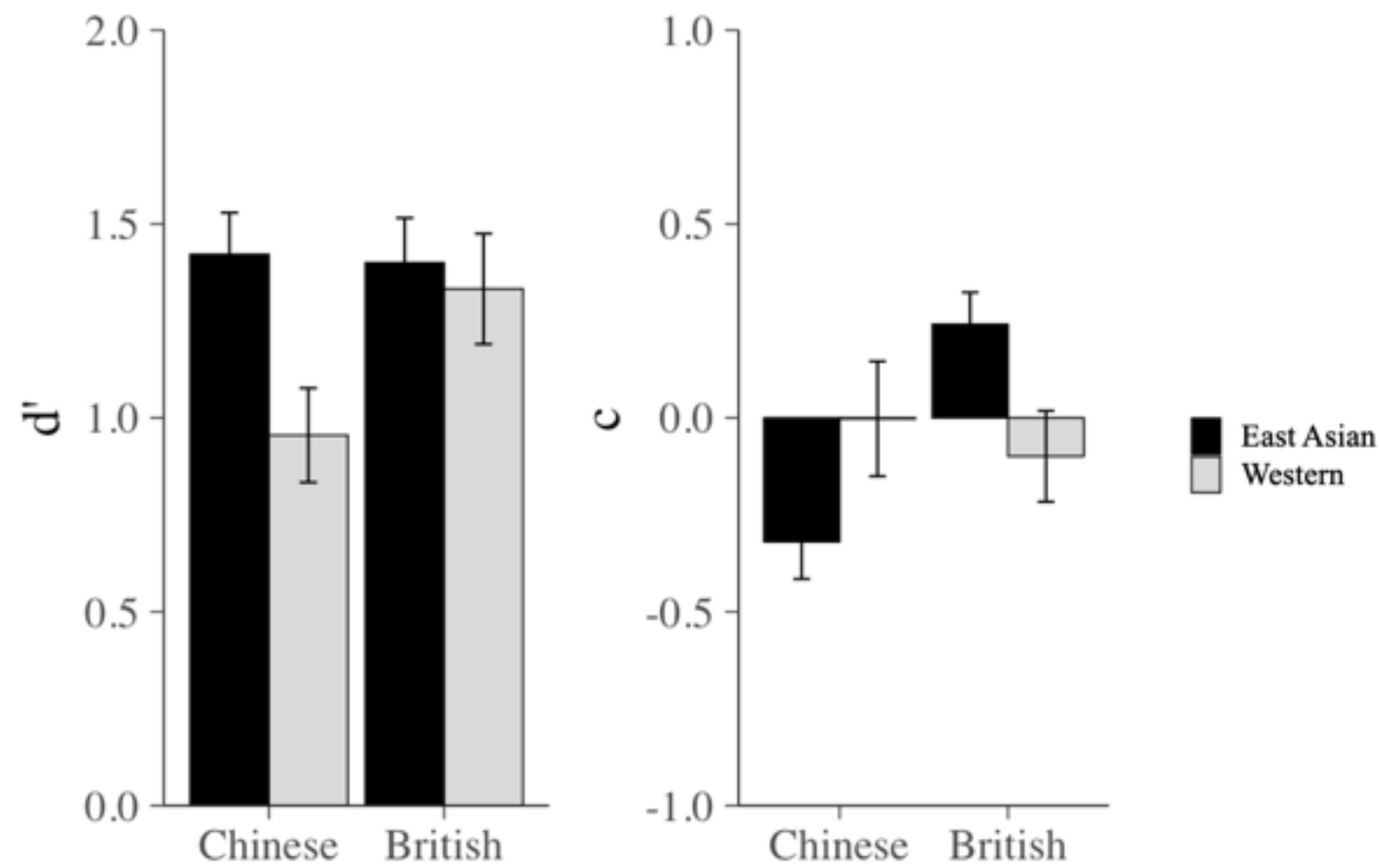

Figure 3. Mean sensitivity and bias values (with $S E$ ) as a function of Culture and Tradition.

\section{Eye Movements}

The first goal of these analyses was to examine whether there was evidence of a difference across cultures in fixations to the theme and contexts of Western and East Asian paintings when initially encoding paintings and then when discriminating target paintings from foils. We did this to explore whether there is an over-riding cultural influence on the spatial distribution of fixations associated with looking across themes and contexts in paintings. Specifically, we hypothesized that Chinese participants would look more at the context, and less at the theme, of paintings compared to British participants. In contrast, if cross-cultural theory in scene perception can be applied to spectatorship of paintings then participants participants drawn from individualistic should present greater focus on the theme ROI than those from collective culture. 
Running head: CROSS-CULTURAL DIFFRENCES IN VIEWING OF PAINTINGS

Outliers and exclusion. Fixations shorter than $60 \mathrm{~ms}$ or longer than $1200 \mathrm{~ms}$ were removed. Fixations that coincided with display onset or the response were also removed. This led to $4 \%$ of data being excluded. The final data set consisted of 207272 fixations in the encoding session and 75624 fixations in the discrimination session. The difference in the overall number of fixations is consistent with the fact that participants performed quite differently in response to encoding and discrimination task requirements.

Data normalization. All eye movement data were log-transformed to increase the normality of the data distribution. To control for differences in the spatial extent of regions across stimuli, the number of fixations was normalised by dividing the number of fixations made within a ROI by the number of pixels within it. Analyses were carried out on normalised number of fixations, mean fixation duration, and the total fixation duration.

The eye movement results for encoding and discrimination sessions are considered separately. With respect to eye movements made at the encoding session, data were analysed with respect to three fixed factors: Culture (Chinese versus British), Tradition (Western versus East Asian), and ROI (theme versus context), as well as their interaction. In a second set of analyses, the data were analysed as in the encoding session but with the addition of a Test Item (target versus foil) fixed factor. The reference levels were Chinese for Culture, East Asian for Tradition, theme for ROI, and foils for Test Item.

Eye Movements at Encoding. With respect to the normalised number of fixations, the main effects of Culture, Tradition and ROI were significant. Chinese participants made more fixations than did British participants, more fixations were made to East Asian than Western paintings and to themes than contexts (see Table 3 and Figure 4). The two-way interactions between ROI and Culture, and between Culture and Tradition were significant as was the three-way interaction between ROI, Culture, and Tradition. Chinese participants made more fixations than British participants to the theme of East Asian paintings $(b=.85, t$ 
$=4.52, p<.001)$. There was no difference between the groups in number of fixations made to the context of East Asian paintings $(t=-.563)$ or in the number of fixations made to the theme or context of Western paintings $(t \mathrm{~s}<.515)$. 
Running head: CROSS-CULTURAL DIFFRENCES IN VIEWING OF PAINTINGS

Table 3

Fixed effect estimates from the Linear Mixed Models for log-transformed number of fixations, log-transformed mean fixation durations, and log-transformed total fixation duration on type of ROIs, Culture, and Tradition at encoding session.

\begin{tabular}{|c|c|c|c|c|c|c|c|c|c|}
\hline & \multicolumn{3}{|c|}{ Fixations } & \multicolumn{3}{|c|}{ Mean fixation duration (ms) } & \multicolumn{3}{|c|}{ Total fixation duration (ms) } \\
\hline & $b$ & $S E$ & $t$ & $b$ & $S E$ & $t$ & $b$ & $S E$ & $t$ \\
\hline Intercept & -8.62 & 0.13 & -61.64 & 5.48 & 0.04 & 144.54 & 8.57 & 0.13 & 63.21 \\
\hline ROI & -1.71 & 0.10 & -16.77 & -0.02 & 0.02 & -1.32 & -0.95 & 0.12 & -7.92 \\
\hline Culture & -0.85 & 0.18 & -4.52 & 0.03 & 0.06 & 0.46 & -0.06 & 0.20 & -0.30 \\
\hline Tradition & -0.55 & 0.20 & -2.73 & -0.04 & 0.06 & -0.66 & 0.08 & 0.20 & 0.42 \\
\hline ROI: Culture & 0.97 & 0.10 & 9.31 & -0.02 & 0.02 & -1.03 & 0.15 & 0.11 & 1.29 \\
\hline ROI: Tradition & -0.11 & 0.14 & -0.78 & -0.01 & 0.02 & -0.33 & -0.99 & 0.17 & -5.72 \\
\hline Culture: Tradition & 0.81 & 0.27 & 2.96 & 0.01 & 0.08 & 0.21 & -0.01 & 0.29 & -0.01 \\
\hline ROI: Culture: Tradition & -1.05 & 0.15 & -6.89 & -0.02 & 0.03 & -0.76 & -0.27 & 0.17 & -1.61 \\
\hline
\end{tabular}

Note. Significant effects are indicated in bold. 
Running head: CROSS-CULTURAL DIFFRENCES IN SPECTATORSHIP OF PAINTINGS

With respect to mean fixation duration, no main effects or interactions reached significance.

With respect to the total fixation duration, participants looked for longer at the theme than the context ROIs. The two-way interaction between ROI and Tradition was significant. Participants spent longer time looking at the context of East Asian paintings than Western paintings $(b=.88, t=5.63, p<.001)$. In contrast, there was no difference in time spent looking at themes across Western and East Asian paintings $(t=-.576)$.

The data confirm the importance of information contained in themes to viewing at encoding. Any influence of culture on viewing at encoding was limited to the number of fixations made to the theme of East Asian paintings such that Chinese participants made more fixations than did British participants. There was no evidence to support a general increased viewing of contexts by Chinese relative to British participants. 

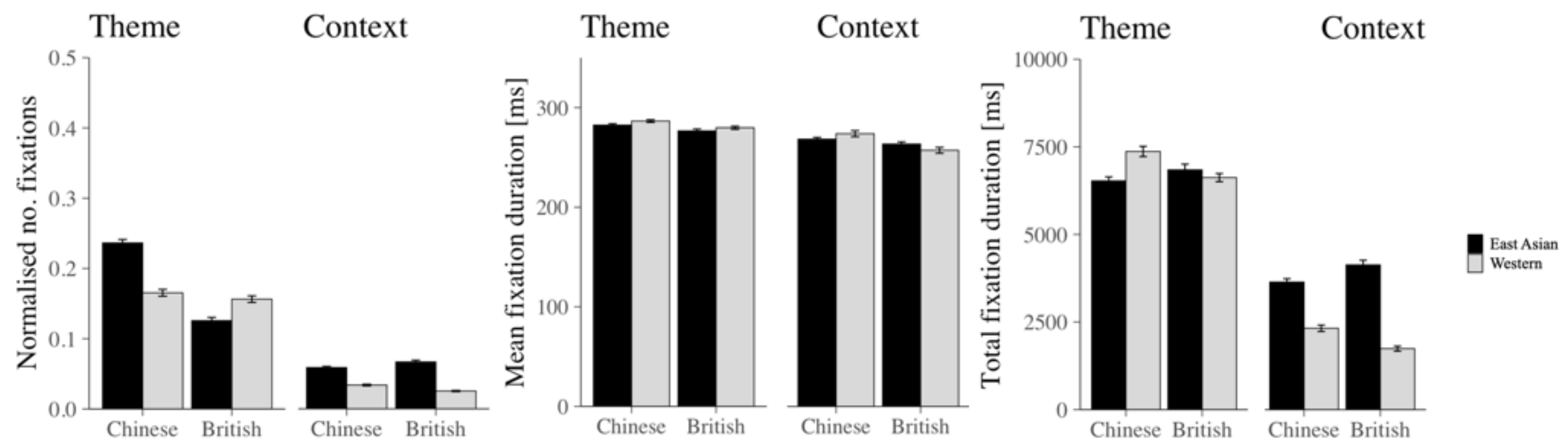

Figure 4. Normalised number of fixations, mean fixation durations, and total fixation duration (with $S E$ ) as a function of ROI, Culture, and Tradition in the encoding session. 
Running head: CROSS-CULTURAL DIFFRENCES IN SPECTATORSHIP OF PAINTINGS

Table 4

Fixed effect estimates from the Linear Mixed Models for log-transformed number of fixations, log-transformed mean fixation durations, and logtransformed total fixation duration on type of ROIs, Culture, Tradition, Presentation at discrimination session.

\begin{tabular}{|c|c|c|c|c|c|c|c|c|c|}
\hline & \multicolumn{3}{|c|}{ Fixations } & \multicolumn{3}{|c|}{ Mean fixation duration (ms) } & \multicolumn{3}{|c|}{ Total fixation duration (ms) } \\
\hline & $b$ & $S E$ & $t$ & $b$ & $S E$ & $t$ & $b$ & $S E$ & $t$ \\
\hline Intercept & -9.20 & 0.10 & 96.62 & 5.43 & 0.04 & 155.99 & 7.70 & 0.09 & -85.64 \\
\hline ROI & -2.11 & 0.08 & -26.69 & -0.03 & 0.02 & -1.76 & -0.98 & 0.07 & -13.31 \\
\hline Tradition & -1.35 & 0.13 & -10.01 & 0.02 & 0.05 & 0.41 & -0.02 & 0.13 & -0.13 \\
\hline Test Item & -0.43 & 0.09 & -4.75 & -0.02 & 0.02 & -1.60 & -0.16 & 0.05 & -3.08 \\
\hline Culture: Tradition & 0.41 & 0.16 & 2.59 & -0.09 & 0.07 & -1.88 & 0.31 & 0.19 & -1.64 \\
\hline ROI: Test Item & 0.14 & 0.05 & 3.08 & 0.07 & 0.02 & 3.42 & -0.02 & 0.05 & -0.39 \\
\hline Culture: Test Item & 0.15 & 0.04 & 3.66 & 0.01 & 0.02 & 0.11 & 0.15 & 0.07 & 2.27 \\
\hline Tradition: Test Item & 0.32 & 0.12 & 2.73 & 0.04 & 0.02 & 1.53 & -0.06 & 0.08 & -0.78 \\
\hline ROI: Culture: Tradition & -0.39 & 0.17 & -2.27 & -0.04 & 0.03 & -0.88 & -0.42 & 0.16 & -2.59 \\
\hline
\end{tabular}

Note. Significant effects are indicated in bold. 
Running head: CROSS-CULTURAL DIFFRENCES IN SPECTATORSHIP OF PAINTINGS

Eye movements at Discrimination. With respect to the number of fixations, more fixations were made to the theme than the context, to East Asian than Western paintings, and to foils than targets (see Table 4). The interactions between ROI and Tradition, Culture and Tradition, and the three-way interaction between ROI, Tradition, and Culture were all significant. In addition, the interactions between ROI and Test Item, Culture and Test Item, Tradition and Test Item, and Culture, Tradition, and Test Item, as well as the four-way interaction between ROI, Culture, Tradition, and Test Item were all significant (see Figure 5). The number of fixations made to the context did not change with Culture, Tradition or Test Item $(t s<3.07)$. Likewise, the number of fixations made to theme of Western paintings did not change with Culture or Test Item $\left(t_{\mathrm{s}}<|2.61|\right)$. In contrast, Chinese participants made more fixations to the theme of East Asian paintings when viewing foils than targets $(b=.43, t$ $=4.75, p<.001)$. In contrast, the number of fixations made by British participants to the theme of East Asian paintings did not differ across foils and targets $(b=.28, t=3.04, p=$ $.28)$.

With respect to the mean fixation duration, the two-way interaction between ROI and Tradition was significant. Participants made longer fixations to the context than the theme of Western but not East Asian paintings $(b=-.04, t=-2.88, p=.02 ; b=.01, t=.64, p=.99$; respectively). The interaction between ROI and Test Item was significant, however none of the comparisons approached significance $(t \mathrm{~s}<|.901|)$.

With respect to total fixation duration, longer fixations were made to the theme than context and to foil than target paintings. The interactions between ROI and Tradition, ROI, Tradition and Culture, Culture and Test Item, ROI, Tradition and Test Item, and four-way interaction between ROI, Tradition, Culture and Test Item were all significant. Total fixation duration, that is the overall time spent fixating the context, did not change with Culture, Tradition or Test Item $(t \mathrm{~s}<3.12)$. Likewise, the total fixation duration for looking to the 
theme for East Asian paintings did not change with Culture or Test item $(t \mathrm{~s}<3.08)$. In contrast, British and Chinese participants had longer total fixation durations when looking at the theme of Western paintings when target, rather than foil paintings, were discriminated ( $b$ $=.21, t=3.67, p=.03 ; b=.22, t=4.04, p=.01$; respectively). However, there was no difference between British than Chinese participants when the theme of targets or foils were viewed in Western paintings $(t \mathrm{~s}<|1.91|)$.

In sum, the data from the discrimination session confirm the hypothesis that more eye movements would be made to foils than targets. However, this increase in the number of fixations on foils compared with targets did not amplify effects of culture on viewing though a number of effects of culture were present across both targets and foils. Evidence of interactions involving culture and tradition were present in the number of fixations and the total fixation duration. In both cases the interactions were focussed on changes in looking at the theme across foils and targets and not the context. Overall, the analysis of the eye movement data in relation to themes and contexts provides evidence of an influence of culture on the viewing of the theme of paintings when participants were required to discriminate targets from foils. However, and importantly, it provides no evidence in support of an increased focus on the context by Chinese participants compared to British participants. 
Running head: CROSS-CULTURAL DIFFRENCES IN SPECTATORSHIP OF PAINTINGS
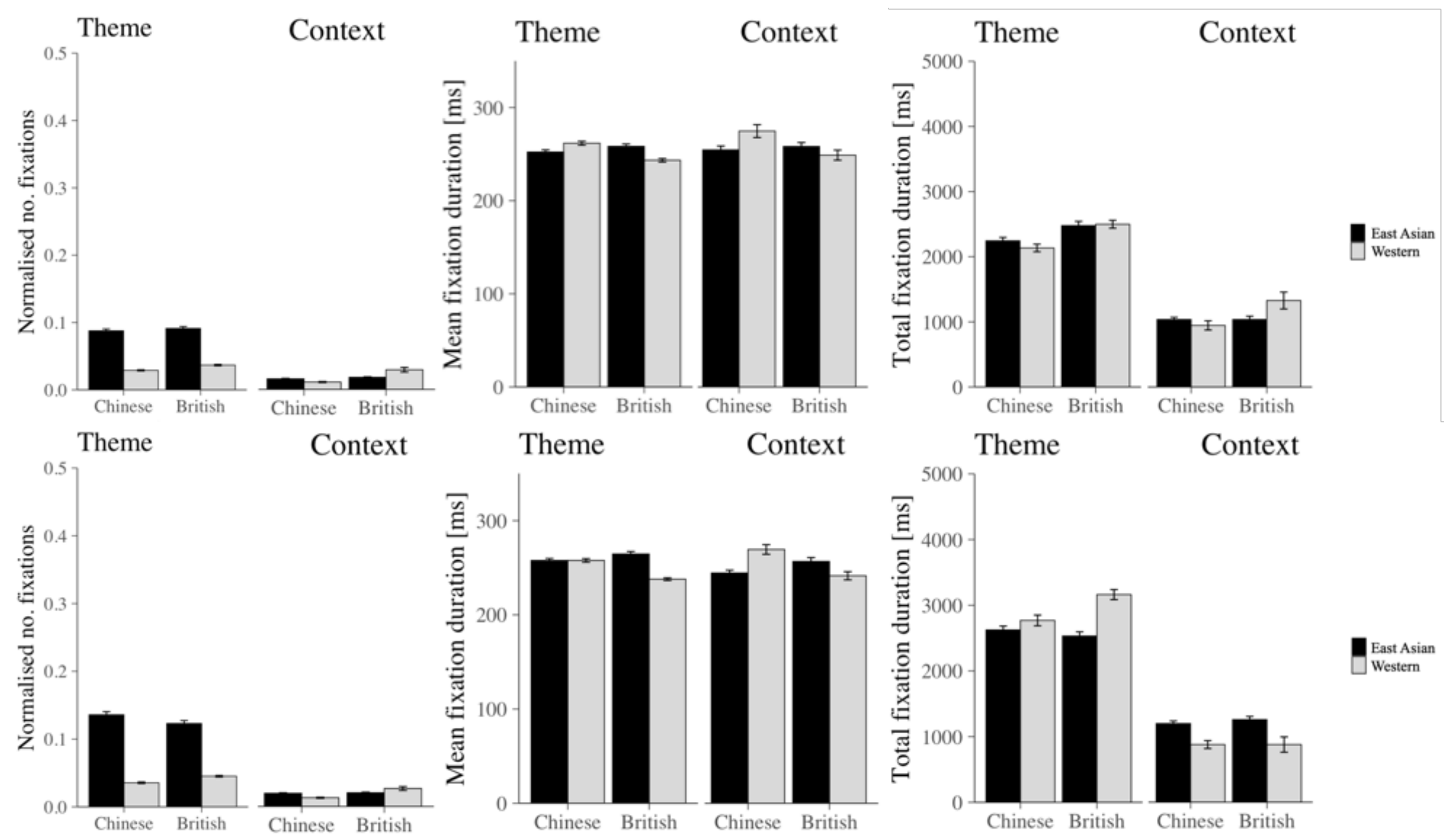

East Asian 
Figure 5. Normalised number of fixations, mean fixation durations, and total fixation duration (with $S E$ ) as a function of ROI, Culture, and Tradition in the discrimination session. The top panel shows data for target paintings, when the bottom panel shows data for foil paintings. 
Running head: CROSS-CULTURAL DIFFRENCES IN SPECTATORSHIP OF PAINTINGS

\section{Fixations to faces}

We now turn to explore the influence of culture on eye movements to faces and to consider these alongside those made to the remainder of the theme (the r-theme) and context. These analyses explore our second hypothesis, that a mismatch relative to a match between a participant's culture and the tradition from which a painting is drawn will influence eye movements made at encoding and discrimination by virtue of the other race effect on viewing of paintings. Fixations to the theme ROI were re-coded, and re-analysed, in terms of whether fixations were made to faces or to the remainder of the theme once fixations to faces were removed. Figure 6 shows means $(S E)$ as a function for ROI, Tradition and Culture at encoding and Figure 7 shows means $(S E)$ as a function for ROI, Tradition, Culture and Test Item at discrimination. Here, we only consider interactions involving Culture and Tradition relating to the face ROI. However, full LMM results are presented in the Tables 5 and 6. 


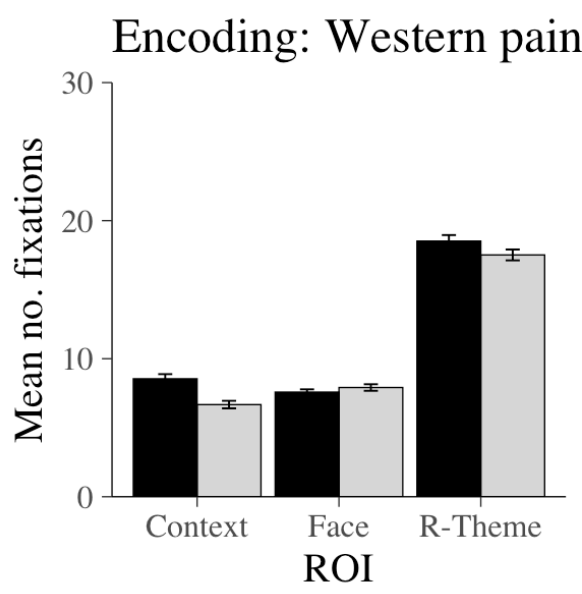

Encoding: Western paintings

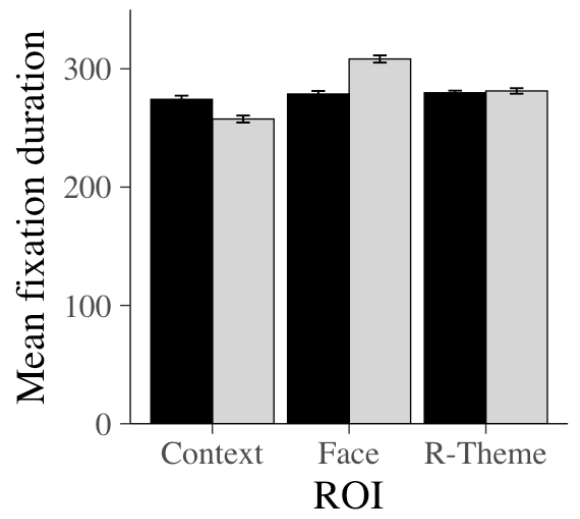

Encoding: Western paintings

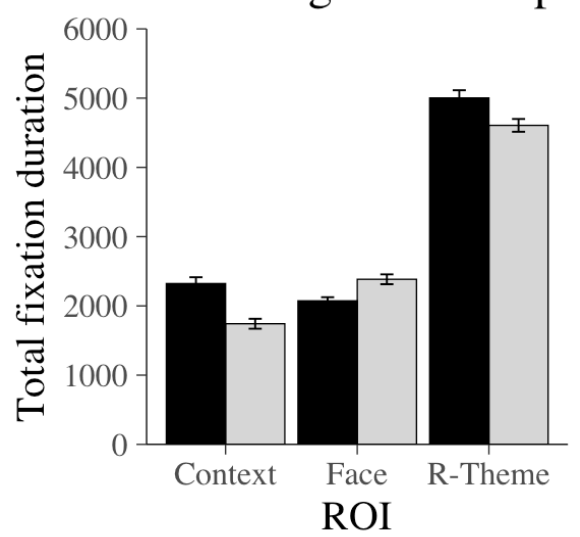

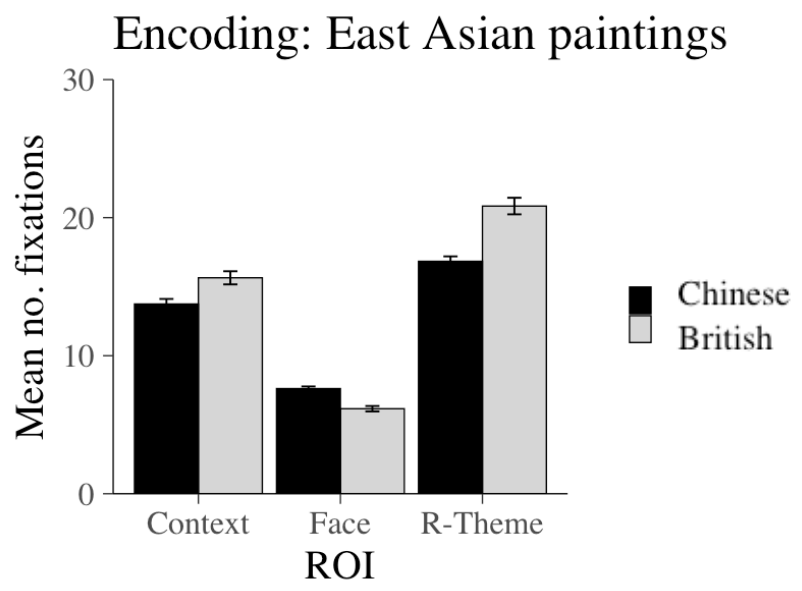

Encoding: East Asian paintings

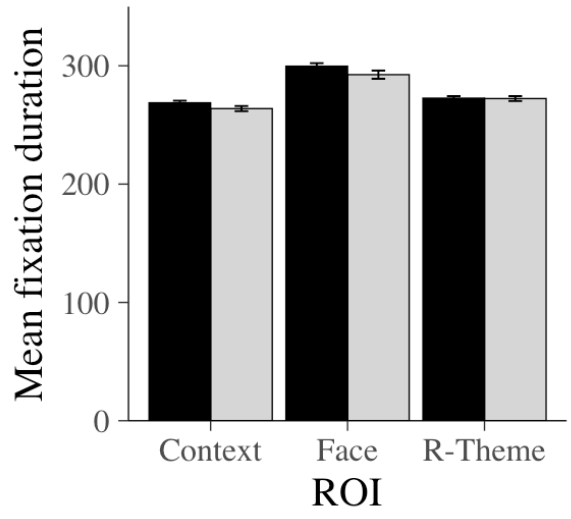

Chinese

British

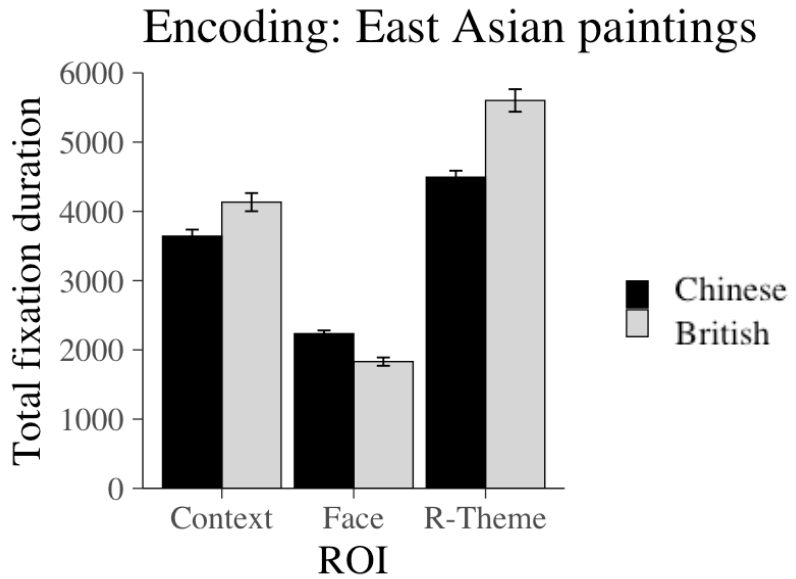

Figure 6. Mean $(S E)$ number of fixations, mean fixation duration and total fixation duration as a function of ROI, Tradition, and Culture group in the encoding session. 
Table 5

Fixed effect estimates from the Linear Mixed Models for log-transformed number of fixations, log-transformed mean fixation durations, and logtransformed total fixation duration on type of ROIs, Culture, and Tradition at encoding session.

\begin{tabular}{|c|c|c|c|c|c|c|c|c|c|}
\hline & \multicolumn{3}{|c|}{ Fixations } & \multicolumn{3}{|c|}{ Mean fixation duration (ms) } & \multicolumn{3}{|c|}{ Total fixation duration (ms) } \\
\hline & $b$ & $S E$ & $t$ & $b$ & $S E$ & $t$ & $b$ & $S E$ & $t$ \\
\hline Intercept & 2.52 & 0.12 & 20.42 & 5.58 & 0.04 & 137.72 & 8.10 & 0.13 & -62.35 \\
\hline $\mathrm{ROI}[$ residual theme vs context] & -0.43 & 0.04 & -11.13 & -0.03 & 0.01 & -2.16 & -0.46 & 0.04 & -10.93 \\
\hline ROI[residual theme vs faces] & 0.82 & 0.03 & -32.64 & 0.07 & 0.09 & 7.83 & -0.74 & 0.03 & -27.20 \\
\hline Culture & 0.14 & 0.18 & 0.64 & -0.02 & 0.06 & -0.39 & 0.09 & 0.19 & 0.49 \\
\hline Tradition & 0.01 & 0.16 & 0.08 & 0.05 & 0.05 & 0.97 & 0.07 & 0.17 & 0.39 \\
\hline ROI[residual theme vs context]: Culture & 0.02 & 0.05 & 0.49 & -0.01 & 0.02 & -0.11 & 0.02 & 0.05 & 0.39 \\
\hline ROI[residual theme vs faces]: Culture & -0.49 & 0.04 & -12.78 & -0.05 & 0.01 & $-\mathbf{3 . 3 3}$ & -0.53 & 0.04 & -12.84 \\
\hline ROI[residual theme vs context]: Tradition & -0.69 & 0.06 & -12.03 & -0.03 & 0.02 & -1.55 & -0.72 & 0.06 & -11.78 \\
\hline ROI[residual theme vs faces]: Tradition & 0.02 & 0.07 & 0.25 & -0.13 & 0.03 & -4.97 & -0.11 & 0.08 & -1.49 \\
\hline Culture: Tradition & -0.01 & 0.19 & -0.04 & -0.03 & 0.06 & -0.44 & -0.04 & 0.20 & -0.19 \\
\hline ROI[residual theme vs context]: Culture: Tradition & 0.02 & 0.08 & 0.20 & -0.07 & 0.03 & -2.29 & -0.05 & 0.09 & -0.59 \\
\hline ROI[residual theme vs faces]: Culture: Tradition & 0.12 & 0.14 & 0.84 & 0.21 & 0.05 & 4.13 & 0.33 & 0.15 & 2.21 \\
\hline
\end{tabular}


Face Encoding. With respect to the number of fixations, the main effect of ROI was qualified by significant two-way interactions between ROI and Culture, ROI and Tradition (Figure 6) but no interactions involving both Culture and Tradition.

With respect to the mean fixation duration, the main effect of ROI was qualified by interactions with Culture, with Tradition, and with both Culture and Tradition. Chinese participants made longer fixations to faces than to the r-theme in East Asian paintings $(b=$ $.07, t=-7.83, p<.001)$ while British participants made longer fixations to faces than to $\mathrm{r}$ theme in Western paintings $(b=-.11, t=-3.99, p<.001)$. In contrast, the difference in mean fixation duration to faces and the r-theme was not significant when Culture and Tradition were consistent $(t \mathrm{~s}<|2.391|)$.

With respect to the total fixation duration, the main effect of ROI was again qualified by interactions with Tradition, Culture and the three-way interaction with both Culture and Tradition. The difference in total fixation durations, when looking at faces and the r-theme, was smaller when Culture and Tradition matched (i.e. the same race condition) than when they did not (Chinese participants: $b=.74, t=27.2, p<.001 ; b=.85, t=12.30, p<.001$; British participants: $b=1.06, t=13.30, p<.001 ; b=1.27, t=40.64, p<.001$; respectively).

In sum, the match (or mismatch) of participant culture and painting tradition influences the extent of looking at faces (and the r-theme) at encoding. A match leads to more looking at faces and less looking at the r-theme, relative to a mismatch.

Face Discrimination. With respect to the number of fixations, the main effect of ROI was qualified by an interaction with Tradition and a three-way interaction between ROI, Tradition and Culture. Pairwise comparisons revealed that none of these interactions was contributed to by fixations to faces $(t \mathrm{~s}<|.866|$; Figure 7$)$.

With respect to mean fixation duration, the main effect of ROI was qualified by an interaction with Culture and a three-way interaction between ROI, Culture, and Tradition. 
Pairwise comparisons revealed that none of these interactions was contributed to by fixations to faces $(t \mathrm{~s}<|1.55|)$.

With respect to the total fixation duration, a main effect of ROI was qualified by the interaction with Tradition and a three-way interaction with Tradition and Culture. Pairwise comparisons revealed that none of these interactions was contributed to by fixations to faces $(t \mathrm{~s}<|.942|)$

In sum, there was no reliable evidence of either Culture or Tradition on the viewing of faces at discrimination. 
Table 6

Fixed effect estimates from the Linear Mixed Models for log-transformed number of fixations, log-transformed mean fixation durations, and

log-transformed total fixation duration on type of ROIs, Culture, Tradition and Test item at discrimination session.

\begin{tabular}{|c|c|c|c|c|c|c|c|c|c|}
\hline & \multicolumn{3}{|c|}{ Fixations } & \multicolumn{3}{|c|}{ Mean fixation duration } & \multicolumn{3}{|c|}{ Total fixation duration } \\
\hline & $b$ & $S E$ & $t$ & $\underline{b}$ & $S E$ & $t$ & $b$ & $S E$ & $t$ \\
\hline Intercept & 1.81 & 0.08 & 22.20 & 5.45 & 0.04 & 151.18 & 7.26 & 0.09 & 81.97 \\
\hline ROI[residual theme vs context] & -0.51 & 0.08 & -6.30 & 0.02 & 0.02 & 0.97 & -0.49 & 0.09 & -5.56 \\
\hline ROI[residual theme vs faces] & -0.76 & 0.07 & -10.69 & 0.13 & 0.03 & 5.18 & -0.63 & 0.08 & -7.75 \\
\hline Culture & -0.02 & 0.11 & -0.18 & 0.04 & 0.05 & 0.84 & 0.03 & 0.12 & 0.21 \\
\hline Tradition & 0.25 & 0.12 & 2.07 & -0.04 & 0.05 & -0.84 & 0.20 & 0.13 & 1.58 \\
\hline Test Item & -0.16 & 0.05 & -3.05 & -0.02 & 0.02 & -0.77 & -0.17 & 0.05 & -3.20 \\
\hline ROI[residual theme vs context]: Culture & -0.07 & 0.12 & -0.59 & -0.02 & 0.03 & -0.80 & -0.10 & 0.13 & -0.75 \\
\hline ROI[residual theme vs faces]: Culture & -0.14 & 0.10 & -1.33 & -0.07 & 0.04 & -1.96 & -0.22 & 0.12 & -1.82 \\
\hline ROI[residual theme vs context]: Tradition & -0.77 & 0.12 & -6.34 & -0.00 & 0.03 & -0.06 & -0.76 & 0.13 & -5.83 \\
\hline ROI[residual theme vs faces]: Tradition & -0.20 & 0.10 & -1.95 & -0.06 & 0.04 & -1.63 & -0.26 & 0.12 & -2.25 \\
\hline Culture: Tradition & -0.26 & 0.17 & -1.57 & 0.05 & 0.08 & 0.65 & -0.22 & 0.18 & -1.19 \\
\hline ROI[residual theme vs context]: Test Item & -0.12 & 0.06 & -2.01 & 0.05 & 0.03 & 1.85 & -0.08 & 0.06 & -1.19 \\
\hline ROI[residual theme vs faces]: Test Item & -0.14 & 0.05 & -2.68 & -0.01 & 0.02 & -0.46 & -0.16 & 0.06 & -2.64 \\
\hline
\end{tabular}




\section{Culture: Test Item}

Tradition: Test Item

ROI[residual theme vs context]: Culture: Tradition

ROI[residual theme vs faces]: Culture: Tradition

ROI[residual theme vs context]: Culture: Test Item

ROI[residual theme vs faces]: Culture: Test Item

ROI[residual theme vs context]: Tradition: Test Item

ROI[residual theme vs faces]: Tradition: Test Item

Culture: Tradition: Test Item

ROI[residual theme vs context]: Culture: Tradition: Test Item

$\begin{array}{lll}0.10 & 0.06 & 1.76 \\ -0.13 & 0.08 & -1.71 \\ 0.40 & 0.18 & \mathbf{2 . 2 5} \\ 0.32 & 0.15 & \mathbf{2 . 0 9} \\ 0.06 & 0.08 & 0.66 \\ 0.08 & 0.08 & 0.97 \\ 0.52 & 0.10 & \mathbf{5 . 2 4} \\ 0.12 & 0.08 & 1.52 \\ -0.16 & 0.08 & -1.91 \\ -0.11 & 0.15 & -0.73 \\ 0.10 & 0.12 & 0.82\end{array}$

$\begin{array}{lll}-0.01 & 0.02 & -0.48 \\ 0.02 & 0.03 & 0.53 \\ 0.10 & 0.05 & \mathbf{2 . 1 2} \\ 0.09 & 0.06 & 1.67 \\ -0.04 & 0.04 & -1.15 \\ 0.01 & 0.04 & 0.15 \\ -0.02 & 0.04 & -0.58 \\ 0.07 & 0.03 & 1.94 \\ 0.00 & 0.04 & 0.07 \\ 0.00 & 0.06 & 0.03 \\ -0.05 & 0.05 & -0.97\end{array}$

0.09

0.06

1.38

ROI[residual theme vs faces]: Culture: Tradition: Test Item

$\begin{array}{lll}0.10 & 0.12 & 0.82\end{array}$

$-0.05$

$\begin{array}{lll}-0.11 & 0.08 \quad-1.48\end{array}$

$\begin{array}{lll}0.51 & 0.19 \quad \mathbf{2 . 6 3}\end{array}$

$\begin{array}{lll}0.41 \quad 0.17 & \mathbf{2 . 3 9}\end{array}$

$\begin{array}{lll}0.02 & 0.09 & 0.18\end{array}$

$\begin{array}{lll}0.08 & 0.09 \quad 0.95\end{array}$

$0.49 \quad 0.11 \quad \mathbf{4 . 5 6}$

$\begin{array}{lll}0.19 & 0.09 & \mathbf{2 . 1 6}\end{array}$

$\begin{array}{lll}-0.15 & 0.09 \quad-1.64\end{array}$

$\begin{array}{lll}-0.12 & 0.16 & -0.75\end{array}$

Note. Significant effects are indicated in bold. 


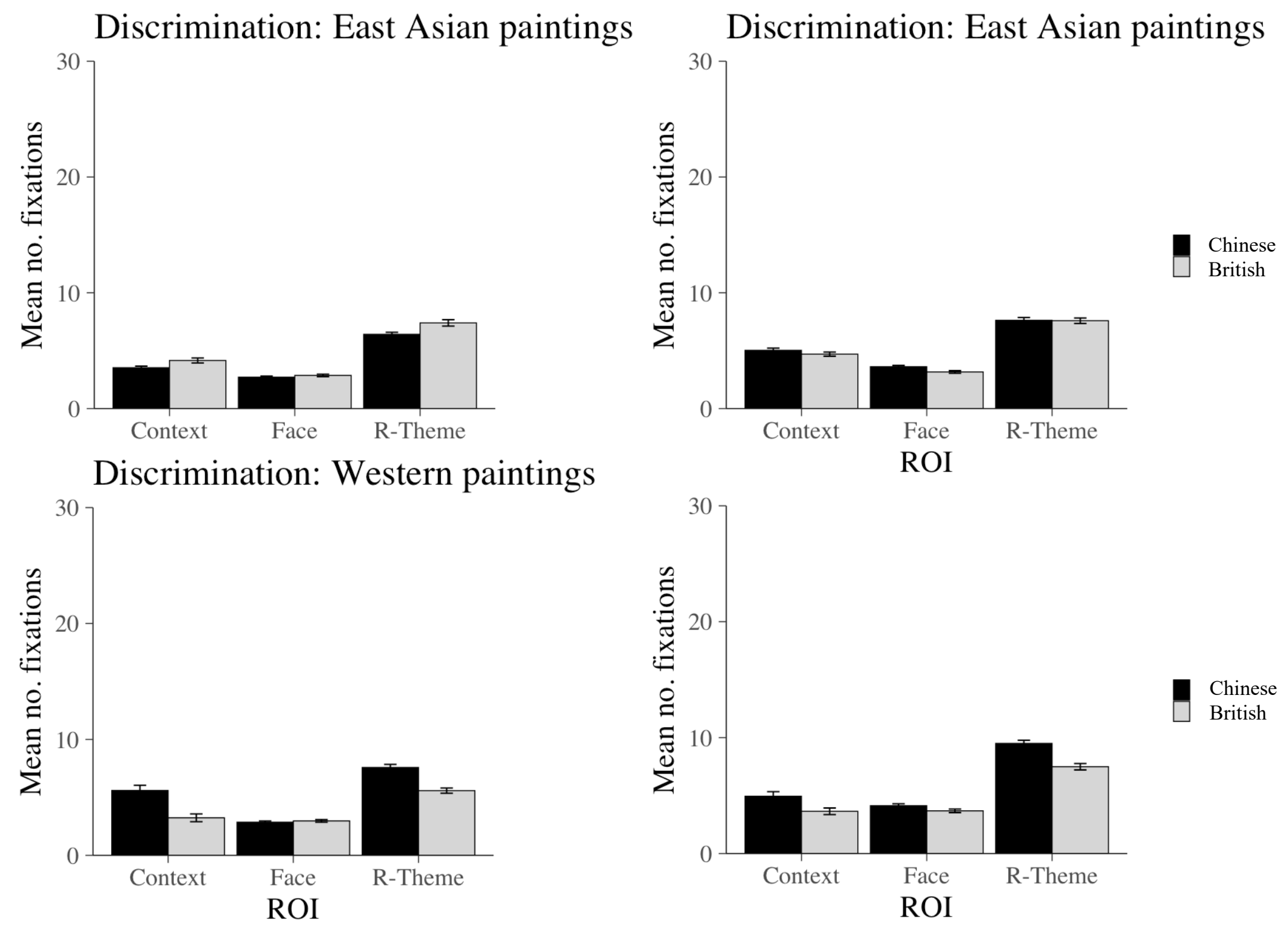


Discrimination: East Asian painting

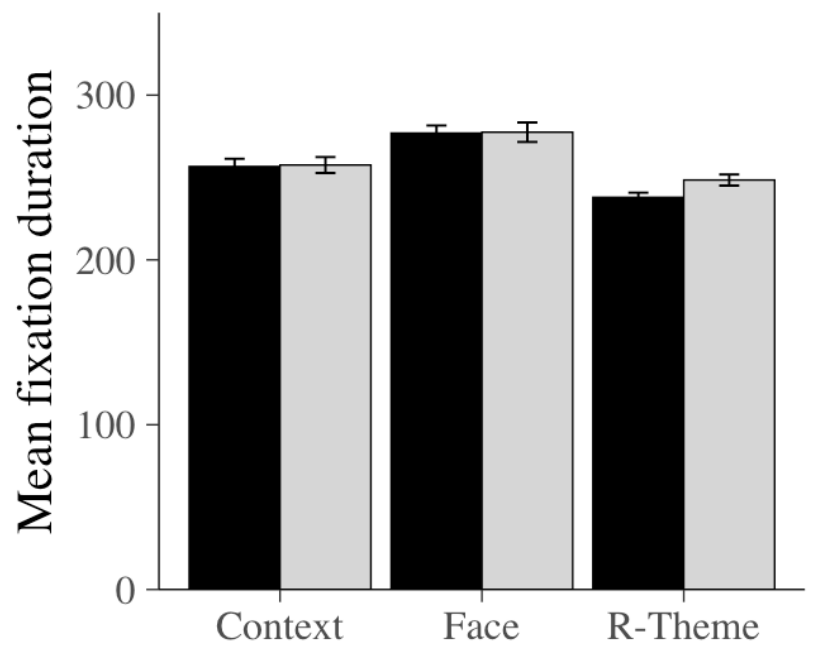

Discrimination: East Asian paintings

Discrimination: Western paintings
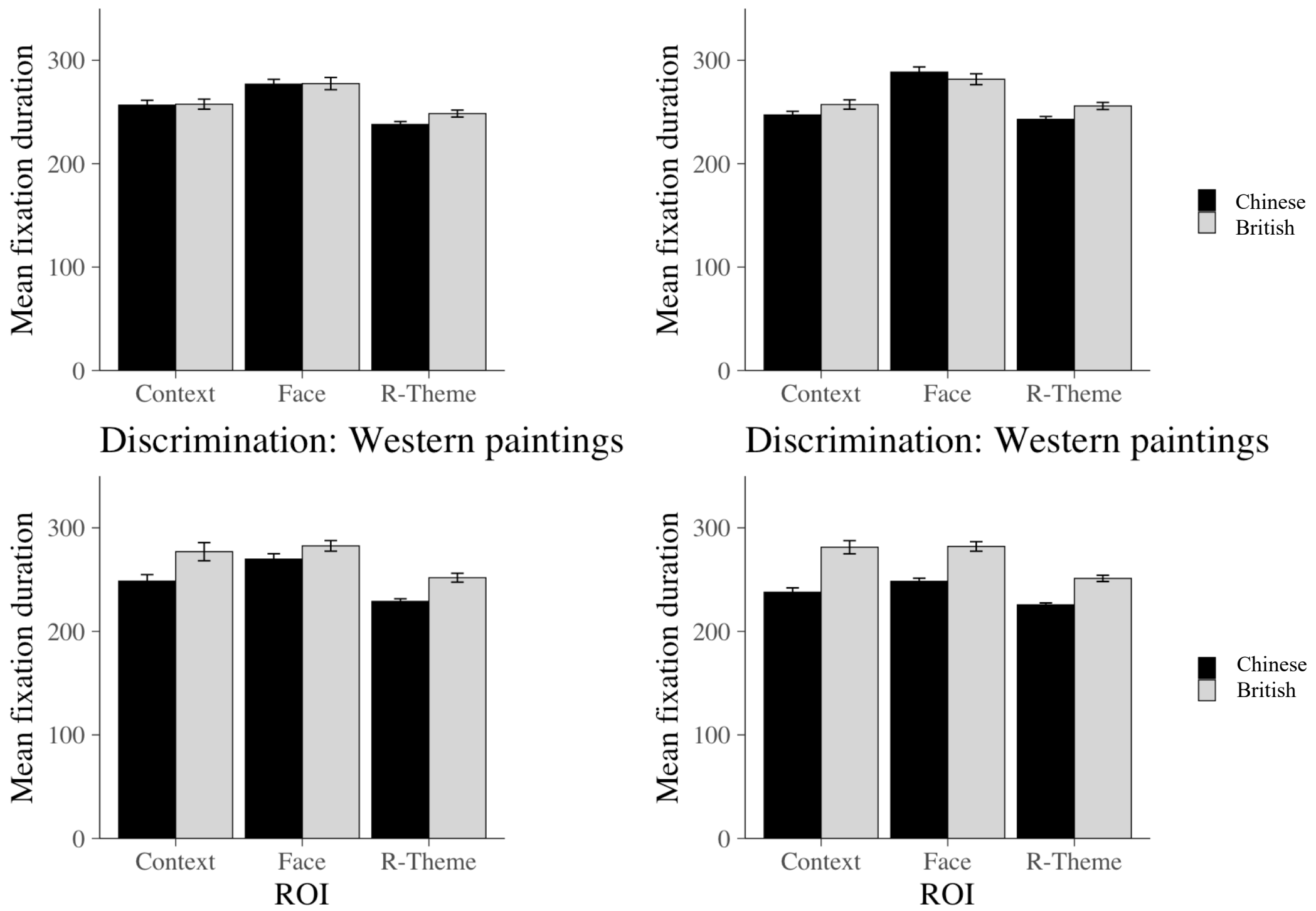

Discrimination: Western paintings

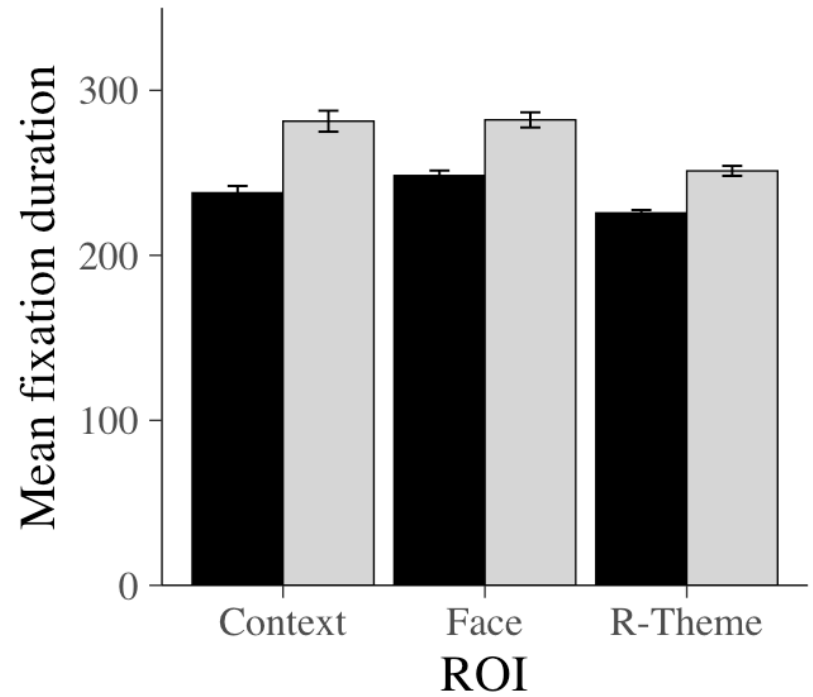

Chinese

British 

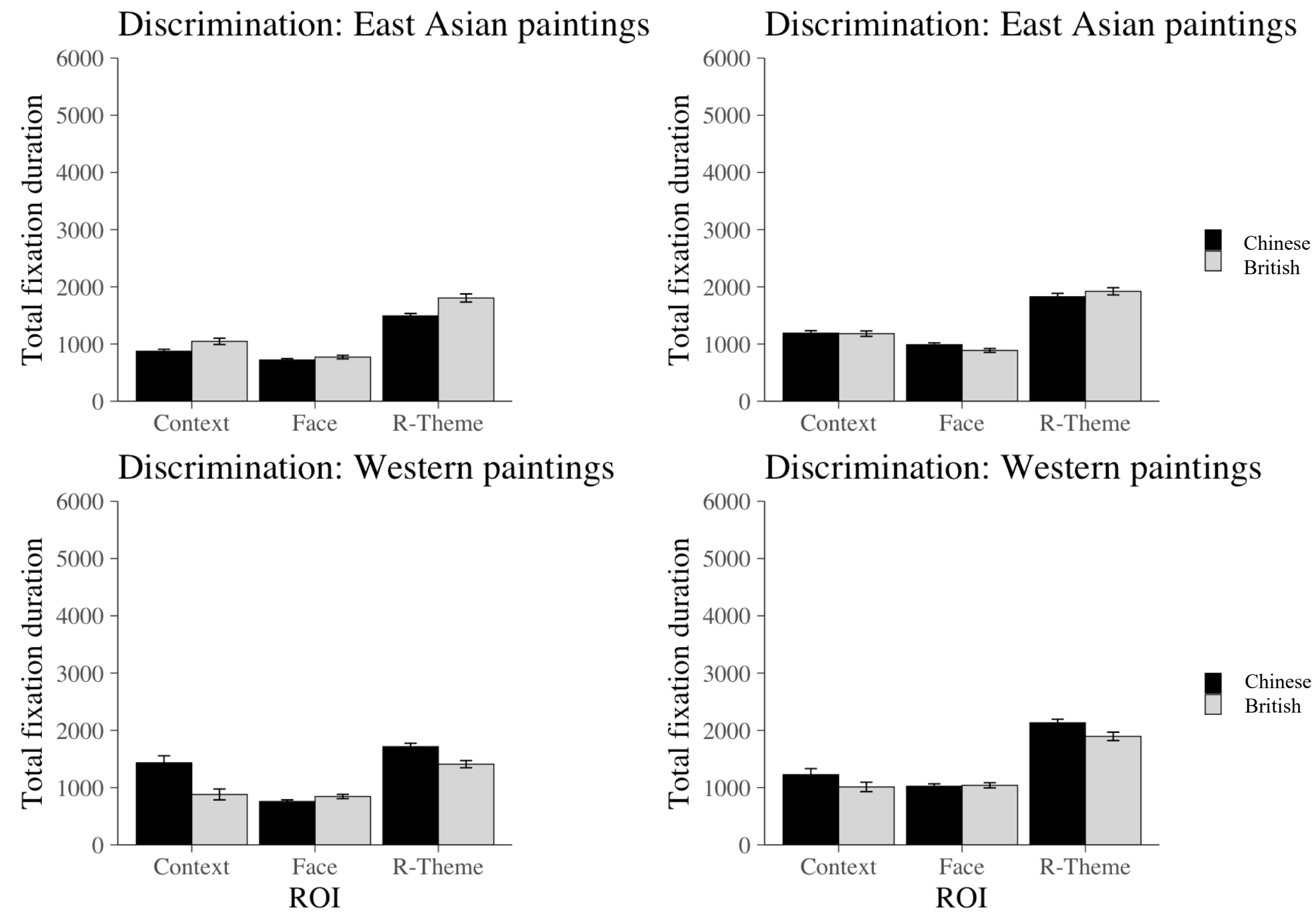
Figure 7. Mean $(S E)$ number of fixations, mean fixation duration and total fixation duration as a function of ROI, Tradition, Culture, and Test Item group in the discrimination session. The left side of the figure refers to target and the right to foils paintings. 


\section{Discussion}

The present study examined the influence of culture on the viewing of Western and East Asian paintings in the context of participants performing an old/new discrimination task. We hypothesised that (1) Chinese participants will look more to the context of paintings than British participants; (2) there would be an interaction between participant culture and painting tradition resulting from the influence of the other race effect on viewing, and (3) the effects of culture on eye movements at discrimination would be most striking on trials showing foils than targets.

The only hypothesis supported by the results was that there would be an interaction between participant culture and painting tradition resulting from the influence of the other race effect on viewing. The presence of same-race faces led to more looking at faces and reduced looking at the r-theme and context relative to the presence of other-race faces. We suggest that the mechanism through which this effect occurs is similar to that identified by Goldinger et al. (2009). The effort participants are willing to expend in the processing of other-race faces is reduced relative to own-race faces.

The opposing influence of face race on viewing of faces versus the $r$-theme and context is potentially important. A natural conclusion to draw may be that eye movements to the $r$-theme and the context increase when viewing paintings drawn from an unfamiliar tradition (relative to from a familiar tradition) as a response to the difficulty encoding other race faces. It is important to say that this link is an association and we do not have any evidence that causally links reduced looking at faces to increased looking elsewhere. Nevertheless, if there is a causal link between reduced looking at other race faces and increased looking elsewhere then it seems likely that participants may have been searching for features that would help them when later trying to discriminate targets from foils. 
The extent to which the effect of culture which we reported here on viewing of paintings is related to broader issue of viewing a context in scene perception is unclear. Paintings are a poor test of the hypothesis that people from collectivist cultures look more at the context of real-world scenes than those from individualistic cultures. Paintings guide attention in very specific and different ways from how it is guided in real-world scenes (Pöppel, 2018). The images of the paintings used in the present study are very different form the photographs used in the visuo-cognitive experiments (e.g., Boland et al., 2008; Chua et al., 2005; Rayner et al., 2007). In addition, it may be that our implementation of theme and context regions of interest in paintings is different to the objects and context of real-world scenes. It is the case that the definition of theme and context in paintings is subject to some discussion. Despite all of these qualifiers, it seems striking to us that we have found no evidence of increased viewing of the context by Chinese relative to British participants in the present results.

It might be argued that the null effect in relation to an influence of culture on viewing of the context results from insufficient statistical power to show the effect ${ }^{1}$. There is, however, no numerical evidence of its presence. We are, therefore, reasonably confident that there is no overall influence of culture on the viewing of context in paintings. This confidence is increased by the observation that other studies have also failed to report effects of culture on the viewing of context in scene perception (see Evans et al., 2009; Rayner et al., 2007).

\footnotetext{
${ }^{1}$ While we report no evidence of an effect of culture on the viewing of context, the results show clear evidence of an interaction between particpant culture and painting tradition when considering eye movements to faces. SimR (Green et al., 2016; Green \& Macleod, 2016) was used to estimate the statistical power of revealing this interaction with respect to mean fixation duration and total fixation duration. Given the effect sizes reported in Table 5, the a priori likelihood of incorrectly rejecting the null hypothesis was $42 \%$ and $52 \%$ respectively for the observed effect sizes of mean fixation duration and total fixation duration. Note that previous research has not reported effect sizes for eye movements to other race faces on paintings from mismatch culture, precluding power analysis based on this measure.
} 
It may also be that the present results are affected by more than a cultural influence on attention and individuation. The results may be affected by a cultural influence on decisions about higher-order face properties, for example, aesthetic evaluation (Savazzi et al., 2014), the reading of emotional expressions (Jack et al., 2009), or decisions about 'vitality' (Di Dio et al., 2020). The present results do not allow insight into the particular aspects of face processing that may have influenced the viewing of paintings in the present experiment. Our explanation does not require invoking a minimal explanation of an influence of culture on eye movements to faces. What that influence is, specifically, remains an interesting line of enquiry for future studies to explore.

It has been suggested that differences in perception and memory tasks relating to participants drawn from individualistic and collective culture may be influenced by memory capacity (Millar et al., 2013). Differences in working memory capacity might be a concern in the present study given the Chinese participants performed with marginally lower sensitivity in the discrimination task than British participants (although this difference was limited to a non significant effect in the discrimination of Western paintings). Furthermore, face processing has been shown to have some relationship to memory capacity (Curby \& Gauthier, 2010). The working memory capacity of all participants in the present study was measured using the 3-back task and showed a group difference with Chinese participants having an increased working memory capacity than British participants. The increased working memory capacity of Chinese relative to British participants does mean that the participant groups were not matched on this measure, nevertheless the differences between groups cannot account for the crossover interaction between participant culture and painting tradition found in the eye movement measures.

Apart from differences in the working memory capacity, the sample of British participants tested in this study had, on average, higher executive attention scores than the 
Chinese participants. While it is possible that differences in the executive measure of attention network may have influenced eye movements (Theeuwes et al., 2009) the difference in executive attention cannot be causative with respect to the cross-over interactions between Culture and Tradition that we obtained. Thus, any interpretation of our interactive effects must extend beyond simple accounts relating solely to cross-cultural differences in executive attention.

The experimental design used in the present study required participants to encode target paintings for later discrimination from foils. There is a question of the extent to which the finding of the influence of the match between participant culture and painting tradition on viewing, which seems to reflect processes associated with face attention and perception, would generalise to experiments requiring participants to make other kinds of judgements (e.g. liking ratings). It might be that it is the requirement to discriminate targets from foils that places a premium on attending to faces. This might be the case if, for example, discriminating faces is easier than other objects or features that might be present. It is certainly the case that participants could rely on the presence of faces in paintings and so they may have focussed on these more when it was helpful to do so. It remains an open question, therefore, whether viewing to determine liking would show similar or different results from those reported here.

There are also a number of methodological factors that may be important in respect of the results. Most importantly, a between-subjects design was adopted in the present study. Of course, whilst Culture must, necessarily, be a between-subjects factor in a study such as this, painting tradition could, in principle, have been tested within participants. However, to following such an approach would itself have brought significant obstacles to clarity in the explanation of our effects. A within subjects approach would certainly have led to the possibility of carry-over effects across stimuli in different conditions. The risk of carry over 
effects is particularly significant when painting stimuli are structured very differently across traditions. Of course, under such circumstances, it would be possible to introduce trial order under a mixed-design as an additional fixed factor into the analysis models. However, such an approach would increase model complexity and very likely lead to model overparameterization reduced likelihood of model convergence (Bates et al., 2015; Matuschek et al., 2017). Our first goal in the present study was to investigate our theoretical questions and demonstrate clarity in our findings without the introduction of unnecessary experimental and analytical complexity. It remains the case that the between-subjects design that we opted for in the present experiment was sufficient to demonstrate the influence of the ORE on the viewing of paintings.

A second issue that may be a cause for concern is the difference in the form of the paintings across traditions. For example, the relative areas of theme and context differed across traditions quite markedly. It is not possible to control for such differences in the stimulus sets when using ecologically valid stimuli such as the paintings we selected. However, it is important to remember that the critical findings we report with respect to the other race effect involve crossover interactions between tradition and culture. To reiterate an argument we made earlier, it is important to note that there can be no simple account of these findings in terms of a basic overall difference between the stimulus sets.

A third concern that some may raise relates to our approach of allowing participants to determine their own viewing time at encoding and discrimination. It is certainly the case that paintings are a specific type of complex image created to be viewed over an extended period of time at a pace determined by an individual's degree of engagement. Truncation of the viewing experience through a forced deadline with respect to encoding would have almost certainly influenced participant's strategy at encoding, thereby changing the nature of the encoding experience. To be clear, we wished to examine cross-cultural processing of 
paintings that occurred under natural encoding conditions. It was for this reason that we used a design that allowed the participant themselves to terminate encoding when they felt they had viewed a painting sufficiently effectively to allow them adequate recall in a later discrimination task.

Finally, the Goldinger et al. (2009) study shows the influence of race on encoding for recognition memory to increase overtime. In the present study we hypothesized an overall effect of culture on eye movements to faces rather than a specific time course. The reason for our conservative interpretation in forming the hypothesis was that the complexity of paintings cannot be controlled in the same way as stimuli used in the Goldinger et al study. Making a specific prediction about the time course of encoding that works across paintings requires normalizing paintings across many factors as some paintings will require less encoding effort than others. Our preference was, therefore, to initially test a simplified version of the ORE hypothesis. It is for future studies to explore the time course of the influence of the ORE on the viewing of paintings, given that the current study reports evidence consistent with its presence.

In conclusion, the present study reveals how the spectatorship of representational paintings is influenced by an interaction between the tradition from which paintings are taken and participant culture. The interaction has contrasting effects on the viewing of faces within paintings and the rest of it across culture. 


\section{References}

Arnheim, R. (1971). Art and visual perception. CA: Universityof California Press.

Arnheim, Rudolf. (1982). The power of the center : a study of composition in the visual arts. University of California Press.

Baayen, R. H., Davidson, D. J., \& Bates, D. M. (2008). Mixed-effects modeling with crossed random effects for subjects and items. Journal of Memory and Language, 59(4), 390412. https://doi.org/10.1016/j.jml.2007.12.005

Bao, Y., Yang, T., Lin, X., Fang, Y., Wang, Y., Pöppel, E., \& Lei, Q. (2016). Aesthetic preferences for Eastern and Western traditional visual art: Identity matters. Frontiers in Psychology, 7(1596), 1-8. https://doi.org/10.3389/fpsyg.2016.01596

Bates, D., Mächler, M., Bolker, B. M., \& Walker, S. C. (2015). Fitting linear mixed-effects models using lme4. Journal of Statistical Software, 67(1). https://doi.org/10.18637/jss.v067.i01

Bates, D., Mächler, M., Bolker, B., \& Walker, S. (2014). Fitting Linear Mixed-Effects Models using lme4. Journal of Statistical Software, 67(1), 1-48. https://doi.org/10.18637/jss.v067.i01

Berlyne, D. E. (1971). Aesthetics and Psychobiology. Appleton-Century-Crofts.

Boland, J. E., Chua, H. F., \& Nisbett, R. E. (2008). How we see it: Culturally different eye movement patterns over visual scenes. In K. Rayner, D. Shen, X. Bai, \& G. Yan (Eds.), Cognitive and cultural influences on eye movements (pp. 363-378). Tianjin People's Press/Psychology Press.

Cavanagh, P. (2005). The artist as neuroscientist. Nature, 434, 301-307.

Chua, H. F., Boland, J. E., \& Nisbett, R. E. (2005). Cultural variation in eye movements during scene perception. Proceedings of the National Academy of Sciences of the United States of America, 102(35), 12629-12633. https://doi.org/10.1073/pnas.0506162102 
Chun, M. M., \& Wolfe, J. M. (1996). Just Say No: How Are Visual Searches Terminated When There Is No Target Present? Cognitive Psychology, 30, 39-78.

Curby, K. M., \& Gauthier, I. (2010). To the trained eye: Perceptual expertise alters visual processing. Topics in Cognitive Science, 2(2), 189-201. https://doi.org/10.1111/j.17568765.2009.01058.x

Delahaye, H. (1993). Du peu d'effet de la peinture occidentale en Chine aux XVIIe et XVIIIe siecles. In J. Catherine \& H. Delahaye (Eds.), L'Europe en Chine (pp. 111-135). De Boccard.

Di Dio, C., Massaro, D., Savazzi, F. A., Gallese, V., Garau, T., Gilli, G., \& Marchetti, A. (2020). Beauty in life: An eye-tracking study on young adults' aesthetic evaluation and vitality judgment of pictorial representations of sleeping and dead subjects. PsyCh Journal, 9(4), 458-471. https://doi.org/10.1002/pchj.285

Evans, K., Rotello, C. M., Li, X., \& Rayner, K. (2009). Scene perception and memory revealed by eye movements and receiver-operating characteristic analyses: Does a cultural difference truly exist? Quarterly Journal of Experimental Psychology, 62(2), 276-285. https://doi.org/10.1080/17470210802373720

Fan, J., Mccandliss, B. D., Sommer, T., Raz, A., \& Posner, M. I. (2002). Testing the Efficiency and Independence of Attentional Networks. Journal of Cognitive Neuroscience, 14(3), 340-347. https://doi.org/10.1162/089892902317361886

Goldinger, S. D., He, Y., \& Papesh, M. H. (2009). Deficits in Cross-Race Face Learning: Insights From Eye Movements and Pupillometry. Journal of Experimental Psychology: Learning Memory and Cognition, 35(5), 1105-1122. https://doi.org/10.1037/a0016548 Gombrich, E. (1992). Art and Illusion. A study in the psychology of pictorial representation. Phaidon Press Limited.

Graham, D. J., \& Redies, C. (2010). Statistical regularities in art: Relations with visual 
coding and perception. Vision Research, 50(16), 1503-1509.

https://doi.org/10.1016/j.visres.2010.05.002

Green, P., \& Macleod, C. J. (2016). SIMR: An R package for power analysis of generalized linear mixed models by simulation. Methods in Ecology and Evolution, 7, 493-498. https://doi.org/10.1111/2041-210X.12504

Green, P., MacLeod, C. J., \& Alday, P. (2016). Package 'simr.' https://cran.rproject.org/web/packages/simr/simr.pdf

Harland, B., Gillett, J., Mann, C. M., Kass, J., Godwin, H. J., Liversedge, S. P., \& Donnelly, N. (2014). Modes of Address in Pictorial Art: An Eye Movement Study of Manet's Bar at the Folies-Bergère. Leonardo, 47(3), 241-247.

https://doi.org/10.1162/LEON_a_00676

Hayn-Leichsenring, G. U., Kloth, N., Schweinberger, S. R., \& Redies, C. (2013). Adaptation effects to attractiveness of face photographs and art portraits are domain-specific. $I$ Perception, 4(5), 303-316. https://doi.org/10.1068/i0583

Jack, R. E., Blais, C., Scheepers, C., Schyns, P. G., \& Caldara, R. (2009). Cultural Confusions Show that Facial Expressions Are Not Universal. Current Biology, 19(18), 1543-1548. https://doi.org/10.1016/j.cub.2009.07.051

Jakesch, M., \& Leder, H. (2009). Finding meaning in art: Preferred levels of ambiguity in art appreciation. Quarterly Journal of Experimental Psychology, 62(11), 2105-2112. https://doi.org/10.1080/17470210903038974

Ji, L. J., Peng, K., \& Nisbett, R. E. (2000). Culture, control, and perception of relationships in the environment. Journal of Personality and Social Psychology, 78(5), 943-955. https://doi.org/10.1037/0022-3514.78.5.943

Kitayama, S., Duffy, S., Kawamura, T., \& Larsen, J. T. (2003). Perceiving and object and its context in different cultures: A Culture Look at New Look. Psychological Science, 
14(3), 201-206. https://doi.org/10.1111/1467-9280.02432

Ko, S. G., Lee, T. H., Yoon, H. Y., Kwon, J. H., \& Mather, M. (2011). How Does Context Affect Assessments of Facial Emotion? The Role of Culture and Age. Psychology and Aging, 26(1), 48-59. https://doi.org/10.1037/a0020222

Lenth, R., Singmann, H., Love, J., Buerkner, P., \& Herve, M. (2019). emmeans: Estimated Marginal Means, aka Least-Squares Means. $R$ package version 1.4.5. https://doi.org/https://CRAN.R-project.org/package=emmeans

Locher, P., Gray, S., \& Nodine, C. (1996). The structural framework of pictorial balance. Perception, 25(12), 1419-1436. https://doi.org/10.1068/p251419

Locher, P., Krupinski, E. a, Mello-Thoms, C., \& Nodine, C. F. (2007). Visual interest in pictorial art during an aesthetic experience. Spatial Vision, 21(1-2), 55-77. https://doi.org/10.1163/156856807782753868

Locher, P., Krupinski, E., \& Schaefer, A. (2015). Art and authenticity: Behavioral and eyemovement analyses. Psychology of Aesthetics, Creativity, and the Arts, 9(4), 356-367. https://doi.org/10.1037/aca0000026

Macmillan, N. A., \& Creelman, C. D. (2004). Detection theory: A user's guide (2nd ed.). NJ: Erlbaum.

Massaro, D., Savazzi, F., Di Dio, C., Freedberg, D., Gallese, V., Gilli, G., \& Marchetti, A. (2012). When art moves the eyes: A behavioral and eye-tracking study. PLoS ONE, 7(5), 1-16. https://doi.org/10.1371/journal.pone.0037285

Masuda, T., Ellsworth, P. C., Mesquita, B., Leu, J., Tanida, S., \& Van de Veerdonk, E. (2008). Placing the Face in Context: Cultural Differences in the Perception of Facial Emotion. Journal of Personality and Social Psychology, 94(3), 365-381. https://doi.org/10.1037/0022-3514.94.3.365

Masuda, T., Gonzalez, R., Kwan, L., \& Nisbett, R. E. (2008). Culture and aesthetic 
preference: Comparing the attention to context of East Asians and Americans.

Personality and Social Psychology Bulletin, 34(9), 1260-1275.

https://doi.org/10.1177/0146167208320555

Masuda, T., \& Nisbett, R. E. (2001). Attending holistically vs. analytically: Comparing the context sensibility of Japanese and American. Journal of Personality and Social Psychology, 81(5), 922-934. https://doi.org/10.1037//0022-35I4.81.5.922

Matuschek, H., Kliegl, R., Vasishth, S., Baayen, H., \& Bates, D. (2017). Balancing Type I error and power in linear mixed models. Journal of Memory and Language, 94, 305315. https://doi.org/10.1016/j.jm1.2017.01.001

Meissner, C. A., \& Brigham, J. C. (2001). Thirty Years of Investigating the Own-Race Bias in Memory for Faces: A Meta-Analytic Review. In Psychology, Public Policy, and Law (Vol. 7, Issue 1, pp. 3-35). American Psychological Association Inc. https://doi.org/10.1037/1076-8971.7.1.3

Melcher, D., \& Cavanagh, P. (2011). Pictorial cues in art and in visualperception. In F. Bacci \& D. Melcher (Eds.), Art and the senses (pp. 359-394). Oxford University Press.

Mickley Steinmetz, K. R., Sturkie, C. M., Rochester, N. M., Liu, X., \& Gutchess, A. H. (2018). Cross-cultural differences in item and background memory: examining the influence of emotional intensity and scene congruency. Memory, 26(6), 751-758. https://doi.org/10.1080/09658211.2017.1406119

Millar, P. R., Serbun, S. J., Vadalia, A., \& Gutchess, A. H. (2013). Cross-cultural differences in memory specificity. Culture and Brain, 1(2-4), 138-157. https://doi.org/10.1007/s40167-013-0011-3

Miyamoto, Y., Nisbett, R. E., \& Masuda, T. (2006). Culture and the Physical Environment. Psychological Science, 17(2), 113-119. https://doi.org/10.1111/j.14679280.2006.01673.x 
Nisbett, R. E., \& Masuda, T. (2003). Culture and point of view. Proceedings of the National Academy of Sciences, 100(19), 11163- 11170.

https://doi.org/https://doi.org/10.1073/pnas.1934527100

Nodine, C. F., Locher, P., \& Krupinski, E. A. (1993). The Role of Formal Art Training on Perception and Aesthetic Judgment of Art Compositions. Leonardo, 26(3), 219-227. https://doi.org/10.2307/1575815

Panofsky, E. (1987). Meaning in Visual Art. Penguin Books.

Pöppel, E. (2018). East of West, West of East: a matter of global and local identity. Cognitive Processing, 19(1), 115-119. https://doi.org/10.1007/s10339-018-0885-2

Rayner, Keith. (2009). The 35th Sir Frederick Bartlett Lecture: Eye movements and attention in reading, scene perception, and visual search. Quarterly Journal of Experimental Psychology, 62(8), 1457-1506. https://doi.org/10.1080/17470210902816461

Rayner, Keith, Li, X., Williams, C. C., Cave, K. R., \& Well, A. D. (2007). Eye movements during information processing tasks: Individual differences and cultural effects. Vision Research, 47(21), 2714-2726. https://doi.org/10.1016/j.visres.2007.05.007

Savazzi, F., Massaro, D., Dio, C. Di, Gallese, V., Gilli, G., \& Marchetti, A. (2014). Exploring Responses to Art in Adolescence: A Behavioral and Eye-Tracking Study. PLoS ONE, 9(7), 1-12. https://doi.org/10.1371/journal.pone.0102888

Shackman, A. J., Sarinopoulos, I., Maxwell, J. S., Pizzagalli, D. A., Lavric, A., \& Davidson, R. J. (2006). Anxiety selectively disrupts visuospatial working memory. Emotion, 6(1), 40-61. https://doi.org/10.1037/1528-3542.6.1.40

Stanley, J. T., Zhang, X., Fung, H. H., \& Isaacowitz, D. M. (2013). Cultural differences in gaze and emotion recognition: Americans contrast more than chinese. Emotion, 13(1), 36-46. https://doi.org/10.1037/a0029209

Team R Core. (2016). R: A Language and Environment for Statistical Computing. R 
Foundation for Statistical Computing.

Theeuwes, J., Belopolsky, A., \& Olivers, C. N. L. (2009). Interactions between working memory, attention and eye movements. Acta Psychologica, 132(2), 106-114. https://doi.org/10.1016/j.actpsy.2009.01.005

Trawinski, T., Mestry, N., Harland, B., Liversedge, S., Godwin, H., \& Donnelly, N. (2019). The Spectatorship of Portraits by Naïve Beholders. Psychology of Aesthetics, Creativity, and the Arts.

Ueda, Y., \& Komiya, A. (2012). Cultural Adaptation of Visual Attention: Calibration of the Oculomotor Control System in Accordance with Cultural Scenes. PLoS ONE, 7(11), 16. https://doi.org/10.1371/journal.pone.0050282

Venables, W. N., \& Ripley, B. D. (2002). Modern Applied Statistics with S. Fourth Edition. Springer.

Yang, L., Li, J., Spaniol, J., Hasher, L., Wilkinson, A. J., Yu, J., \& Niu, Y. (2013). Aging, Culture, and Memory for Socially Meaningful Item-Context Associations: An East-West Cross-Cultural Comparison Study. PLoS ONE, 8(4), 1-7.

https://doi.org/10.1371/journal.pone.0060703 
Appendix A: List of Western paintings used at Encoding and

Discrimination session collapsed by authors and motifs.

\begin{tabular}{|c|c|c|c|}
\hline Author & Title & Year & Moti \\
\hline \multicolumn{4}{|c|}{ Encoding Session } \\
\hline Baldung Grien, Hans & The Three Graces & c. 1540 & 1 \\
\hline Canova, Antonio & The Three Graces Dancing & c. 1799 & 1 \\
\hline Cranach, Lucas the Elder & The Three Graces & 1535 & 1 \\
\hline Furini, Francesco & The Three Graces & c. 1633 & 1 \\
\hline Rubens, Peter Paul & The Three Graces & 1639 & 1 \\
\hline Rafaello Sanzio & The Three Graces & 1504 & 1 \\
\hline Rubens, Peter Paul & $\begin{array}{l}\text { Nature Adoring the Three } \\
\text { Graces }\end{array}$ & c. 1615 & 1 \\
\hline Botticelli, Sandro & Primavera & c. 1482 & 1 \\
\hline Tintoretto & Mercury and the Graces & c. 1576 & 1 \\
\hline Bronkhorst, Jan Gerritsz & The Three Graces & c. 1645 & 1 \\
\hline Moser, Koloman & The Three Graces & 1905 & 1 \\
\hline Carle van Loo & The Three Graces & 1763 & 1 \\
\hline Mathews, Arthur Frank & $\begin{array}{l}\text { Song of the Sea (Three } \\
\text { Graces) }\end{array}$ & c. 1909 & 1 \\
\hline Dali, Salvador & $\begin{array}{l}\text { Enchanted Beach With Three } \\
\text { Fluid Graces }\end{array}$ & 1938 & 1 \\
\hline Delaunay, Robert & La Ville de Paris & 1912 & 1 \\
\hline
\end{tabular}


Scalbert, Jules

Janco, Marcel

Fragonard, Jean_Honore

Etty, Wiliam

Picasso, Pablo

Botticelli, Sandro

Cairo, Francesco del

Catena, Vincenzo

Elsheimer, Adam

Gentileschi, Artemisia

Allori, Cristofano

Giorgione

Riedel, August

Rubens, Peter Paul

Tintoretto

Tiziano

Klimt, Gustav

Valentin de Boulogne

Corot, Jean_Baptiste-

Camille
The Three Graces dancing

with Faun

c. $1877 \quad 1$

The Three Women in Malta

1930

The Three Graces

1756

1

Venus and Her Satellites

1835

1

Three woman

1908

1

Judith Leaving the Tent of

Holofernes

Judith with Head of

Holofernes

c. 1645

2

Judith

1520

2

Judith Beheading Holofernes

1601

2

Judith and Her Maidservant

c. 1614

2

Judith with Head of

1613

2

Holofernes

Judith

c. 1504

2

Judith

1840

2

Judith with Head of

Holofernes

c. 1616

2

Judith and Holofernes

c. 1579

2

Judith

c. 1515

2

Judith I

1901

2

Judith

c. 1626

2

Judith

c. 1872 2 
Moser, Koloman

Mellin, Charles

Piazzetta, Giovanni

Battista

Judith and Holofernes

Judith Victorious over

Cranach, Lucas the Elder

\section{Holofernes}

Carrachi, Agostino

Stuck, Franz

Renoir, Pierre-Auguste

Seurant, Georges

Bazille, Jean-Frederic

Vernet, Claude-Joseph

Cezanne, Paul

Coubert, Gustave

Gaugini, Paul

Fragonard, Jean-Honore

Carracci

Cezanne, Paul

Kirchner, Ernst Ludwig

Cezanne, Paul

Cezanne, Paul

Andre Derain

Picasso, Pablo

Picasso, Pablo

Judith and Holofernes

Holofernes

Juditt
1916

1630

2

c. 1590

1928

c. 1884

c. 1883

3

Bathers (summer Scene)

1869

3

Landscape with Bathers

1783

3

Bathers Beneath a Bridge

c. 1895

1853

1897

c. 1772

1616

c. 1900

c. 1909

c. 1872

c. 1890

1907

1937

1918
2 


\begin{tabular}{|c|c|c|}
\hline Picasso, Pablo & Les Demoiselles d'Avignon & 1907 \\
\hline Walker, Frederick & The Bathers & c. 1866 \\
\hline Matisse, Henri & Joy of Life & c. 1905 \\
\hline Matisse, Henri & Bathers with turtle & 1908 \\
\hline Leighton, Frederic & Odalisque & 1862 \\
\hline Boucher, Francois & Brown Odalisque & 1745 \\
\hline Delacroix, Eugene & Odalisque & 1857 \\
\hline Ingres, Jean-Auguste- & The Grand Odalisque & 1814 \\
\hline Renoir, Pierre-Auguste & Odalisque & 1870 \\
\hline Matisse, Henri & Odalisque, Harmony in Red & c. 1926 \\
\hline Tanoux, Adrien Henri & Odalisque & 1913 \\
\hline Schiovoni, Natale & Odalisque & 1845 \\
\hline Matisse, Henri & Odalisque & 1926 \\
\hline Picasso, Pablo & $\begin{array}{l}\text { The Great Odalisque (after } \\
\text { Ingres) }\end{array}$ & 1907 \\
\hline Picou, Henri Pierre & Odalisque & 1858 \\
\hline Picasso, Pablo & Woman of Algier (Version N) & 1955 \\
\hline Picasso, Pablo & Jacqueline in Turkish Dress & 1955 \\
\hline $\begin{array}{l}\text { Corot, Jean_Baptiste- } \\
\text { Camille }\end{array}$ & The Roman Odalisque & 1843 \\
\hline Fabbi, Fabio & Girls of the Harem & c. 1906 \\
\hline Delacroix, Eugene & The Women of Algiers in Their & 1834 \\
\hline Jonghe, Gustave Leonard & A reclining Odalisque & c. 1870 \\
\hline Fortuny, Maria & The Odalisque & 1861 \\
\hline
\end{tabular}




\begin{tabular}{|c|c|c|c|}
\hline Lefebvre, Jules Joseph & Odalisque & 1874 & 4 \\
\hline Bukovac, Vlaho & Odalisque & 1882 & 4 \\
\hline Botticelli, Sandro & The Birth of Venus & 1486 & 5 \\
\hline Cabanel & The Birth of Venus & 1683 & 5 \\
\hline Fauconnet, Guy Pierre & Venus & 1919 & 5 \\
\hline Titian & The Venus of Urbino & 1538 & 5 \\
\hline Picasso, Pablo & Nude woman with Necklece & 1968 & 5 \\
\hline Cranach, Lucas the Elder & Cupid Complaining to Venus & 1525 & 5 \\
\hline Sustris, Lambert & Venus and Love & 1550 & 5 \\
\hline Matisse, Henri & Venus & 1952 & 5 \\
\hline Rosetti, D. G. & Venus & c. $1863-$ & 5 \\
\hline Velazques, Diego & Venus at her Mirror & 1601 & 5 \\
\hline Gossart, Jan & Venus & c. 1521 & 5 \\
\hline Rubens, Peter Paul & Venus at a Mirror & c. 1615 & 5 \\
\hline Modigliani, Amadeo & Venus-Maja & 1917 & 5 \\
\hline Rembrandt van Rijni & Hendrickje Stoffels as Venus & 1662 & 5 \\
\hline Albani, Francesco & $\begin{array}{l}\text { Venus Attended by Nymphs } \\
\text { and Cupids }\end{array}$ & 1633 & 5 \\
\hline Bollandt, Heinrich & Venus and Amor & c. 1520 & 5 \\
\hline Lambert, Sustris & Venus and Love & 1550 & 5 \\
\hline Boucher, Francois & The Triumph of Venus & 1740 & 5 \\
\hline $\begin{array}{l}\text { Ingres, Jean-Auguste- } \\
\text { Dominique }\end{array}$ & Venus Anadyamene & c. 1825 & 5 \\
\hline Dali, Salvador & Venus Binding Cupids & 1925 & 5 \\
\hline
\end{tabular}




\begin{tabular}{|c|c|c|}
\hline Aachen, Hans von & The three Graces & 1604 \\
\hline Bisson, Eduard & The Three Graces & 1899 \\
\hline Bouvier, Jules Augustus & The Three Graces & 1975 \\
\hline Cranach, Lucas the Elder & The Three Graces & 1531 \\
\hline Delaunay, Robert & The Three Graces & 1912 \\
\hline Frost, William & The Three Graces & c. 1854 \\
\hline Picasso, Pablo & The Three Graces & 1908 \\
\hline Picasso, Pablo & The Three dancers & 1925 \\
\hline Vernon, Emile & The Three Graces & 1917 \\
\hline Rubens, Peter Paul & The Three Graces & 1620 \\
\hline Botticelli, Sandro & Primavera & c. 1482 \\
\hline Bronchorst, Jan Gerritsz & The Three Graces & c. 1645 \\
\hline Dali, Salvador & $\begin{array}{l}\text { Enchanted Beach With Three } \\
\text { Fluid Graces }\end{array}$ & 1938 \\
\hline Etty, Wiliam & Venus and Her Satellites & 1835 \\
\hline Furini, Francesco & The Three Graces & c. 1633 \\
\hline Janco, Marcel & The Three Women in Malta & 1930 \\
\hline Mathews, Arthur Frank & Song of the Sea (Three Graces) & c. 1909 \\
\hline Picasso, Pablo & Three woman & 1908 \\
\hline Rubens, Peter Paul & The Three Graces & c. 1615 \\
\hline Tintoretto & Mercury and the Graces & c. 1576 \\
\hline Botticelli, Sandro & The return Judith to Bethulia & 1427 \\
\hline Carravagio & Judith Beheadinng Holofernes & c. 1598 \\
\hline Cranach, Lucas the Elder & Judith Victorious & c. 1530 \\
\hline
\end{tabular}




\begin{tabular}{|c|c|c|}
\hline Gentileschi, Artemisia & Judith and Holofernes & 1620 \\
\hline Goya, Francisco & Judith and Holofernes & 1819 \\
\hline Klimt, Gustav & Judith II & 1909 \\
\hline Lama, Gulia & Judith and Holofernes & 1730 \\
\hline Vasari, Giorgio & Judith and Holofernes & c. 1554 \\
\hline Bray, Salomon de & $\begin{array}{l}\text { Judith Delivering the Head of } \\
\text { Holofernes }\end{array}$ & 1636 \\
\hline Vermeyen, Jan Cornelisz & Judith with Head of Holofernes & c. 1525 \\
\hline Botticelli, Sandro & $\begin{array}{l}\text { Judith Leaving the Tent of } \\
\text { Holofernes }\end{array}$ & c. 1495 \\
\hline Cairo, Francesco del & Judith with Head of Holofernes & c. 1645 \\
\hline $\begin{array}{l}\text { Corot, Jean_Baptiste- } \\
\text { Camille }\end{array}$ & Judith & c. 1872 \\
\hline Giorgione & Judith & c.1504 \\
\hline Moser, Koloman & Judith and Holofernes & 1916 \\
\hline Mellin, Charles & Judith with Head of Holofernes & 1630 \\
\hline Riedel, August & Judith & 1840 \\
\hline $\begin{array}{l}\text { Piazzetta, Giovanni } \\
\text { Battista }\end{array}$ & Judith and Holofernes & c. 1745 \\
\hline Stuck, Franz & Judith & 1928 \\
\hline Valentin de Boulogne & Judith & c. 1626 \\
\hline Picasso, Pablo & Bathers in Forest & 1908 \\
\hline Wouwerman, Philips & Landscape with Bathers & c. 1660 \\
\hline Cezanne, Paul & Bathers & 1892 \\
\hline
\end{tabular}




\begin{tabular}{|c|c|c|}
\hline Gaugini, Paul & Bathers at Tahiti & 1897 \\
\hline Kirchner, Ernst Ludwig & Three Bathers & 1913 \\
\hline Peter, Jean Baptiste Joseph & The Bathers & c. 1721 \\
\hline Preisler, Jan & Bathers & 1912 \\
\hline Renoir, Pierre-Auguste & The Bathers & 1918 \\
\hline Seurat, Georges & Study for Bathers at Asnieres & 1883 \\
\hline Cezanne, Paul & Bathers & c. 1900 \\
\hline Bazille, Jean-Frederic & Bathers (Summer Scene) & 1869 \\
\hline Carracci & Landscape with Bathers & 1616 \\
\hline Cezanne, Paul & The Large Bathers & c. 1900 \\
\hline Fragonard, Jean-Honore & The Bathers & c. 1772 \\
\hline Walker, Frederick & The Bathers & c. 1866 \\
\hline Gaugini, Paul & The Bathers & 1897 \\
\hline Matisse, Henri & Joy of Life & c. 1905 \\
\hline Picasso, Pablo & Bathers with Toy Boat & 1937 \\
\hline Picasso, Pablo & Bathers & 1918 \\
\hline Courbet, Gustave & The Bathers & 1853 \\
\hline Boucher, Francois & Blond Odalisque & 1752 \\
\hline $\begin{array}{l}\text { Ingres, Jean-Auguste- } \\
\text { Dominique }\end{array}$ & Odalisque with slave & 1842 \\
\hline Matisse, Henri & $\begin{array}{l}\text { Odalisque with a Green Plant } \\
\text { and Screen }\end{array}$ & 1923 \\
\hline Matisse, Henri & Reclining Odalisque & 1926 \\
\hline Picasso, Pablo & Femmes d'Alger & 1955 \\
\hline
\end{tabular}


Renoir, Pierre-Auguste

Parisian Women in Agerian

Costume

Tanoux, Adrien Henri

Weisz, Adolphe

Gervex, Henri

Renoir, Auguste

Bukovac, Vlaho

Corot, Jean_Baptiste-

Camille

Delacroix, Eugene

Ingres, Jean-Auguste-

Dominique

Lefebvre, Jules Joseph

Leighton, Frederic

Picasso, Pablo

Picasso, Pablo

Picou, Henri Pierre

Schiovoni, Natale

Amaury, Duval

Bouguereau, A.

Picasso, Pablo

Giorgione

Titian
Odalisque

Odalisque

Odalisque

Reclining Odalisque

Odalisque

The Roman Odalisque

The Women of Algiers in Their

The Grand Odalisque

Odalisque

Odalisque

Jacqueline in Turkish Dress

The Great Odalisque (after

Ingres)

Odalisque

Odalisque

La Naissance de Venus

The Birth of Venus

Venus et L'Amour

Sleeping Venus

Venus and Music
1872

4

$1904 \quad 4$

$1884 \quad 4$

$1882 \quad 4$

c. 19174

18824

$1843 \quad 4$

$1834 \quad 4$

$1814 \quad 4$

$1874 \quad 4$

18624

$1955 \quad 4$

$1907 \quad 4$

$1858 \quad 4$

$1845 \quad 4$

18625

$1879 \quad 5$

$1957 \quad 5$

c. $1510 \quad 5$

$1547 \quad 5$ 
Rubens, Peter Paul

Girodet de Roucy-Trison, Louis

Tintoretto

Carracci

Poussin, Nicholas

Boucher, Francois

Dali, Salvador

Fauconnet, Guy Pierre

Gossart, Jan

Matisse, Henri

Modigliani, Amadeo

Picasso, Pablo

Rembrandt van Rijni

Rubens, Peter Paul

Sustris, Lambert
Venus Frigda

Mademoiselle Lange as Venus

Venus, Mars and Vulcan

Sleeping Venus

Venus and Satyr

The Triumph of Venus

Venus Binding Cupids

Venus

Venus

Venus

Venus-Maja

Nude woman with Necklace

Hendrickje Stoffels as Venus

Venus at a Mirror

Venus and Love
1614

1798 5

c. $1551 \quad 5$

c. $1602 \quad 5$

$1626 \quad 5$

$1740 \quad 5$

$1925 \quad 5$

$1919 \quad 5$

c. $1521 \quad 5$

$1952 \quad 5$

$1917 \quad 5$

$1968 \quad 5$

$1662 \quad 5$

c. $1615 \quad 5$

$1550 \quad 5$

$\overline{\text { Note. In fourth column is shown motif categories }(1=\text { Three Graces, } 2=\text { Judith, } 3}=$ Bathers, $4=$ Odalisque, $5=$ Venus $)$. 
Appendix B: List of East Asian paintings used at Encoding and

Discrimination session collapsed by authors and motifs.

\begin{tabular}{|c|c|c|c|}
\hline Artist & Title & Dynasty & Motif \\
\hline \multicolumn{4}{|c|}{ Encoding Session } \\
\hline unknown & Samantabhadra & Tang & 1 \\
\hline unknown & Illustration of the Buddhist Scripture & Wu Dai & 1 \\
\hline Guanpeng, Ding & The solemn image of Bodhisattva & Qing & 1 \\
\hline unknown & Bodhisattva leads the dead to paradise & Tang & 1 \\
\hline unknown & The Portrait of Samantabhadra & Song & 1 \\
\hline unknown & King of the Inferno & Song & 1 \\
\hline unknown & Water moon kuan-yin & Song & 1 \\
\hline Liying, Jin & The Portrait of Avalokitesvara & Qing & 1 \\
\hline Daqian, Zhang & The Portrait of Avalokitesvara & CHRP & 1 \\
\hline Daqian, Zhang & Avalokitesvara in white dress & CHRP & 1 \\
\hline Daqian, Zhang & The Portrait of Avalokitesvara & CHRP & 1 \\
\hline Daqian, Zhang & Water moon kuan-yin & CHRP & 1 \\
\hline unknown & Thousand-hand Bodhisattva & Song & 1 \\
\hline unknown & Shakya Muni and Bodhisattva & Yuan & 1 \\
\hline unknown & $\begin{array}{l}\text { Nyoirin Kannon sitting a top island paradise } \\
\text { Fudaraku }\end{array}$ & Yuan & 1 \\
\hline unknown & The Bodhisattva Avalokitesvara & Qing & 1 \\
\hline Xigui, $\mathrm{Hu}$ & The Portrait of Avalokitesvara & Qing & 1 \\
\hline unknown & Lotus Kwun Yin & Ming & 1 \\
\hline Guanpeng, Ding & The Portrait of Avalokitesvara & Qing & 1 \\
\hline
\end{tabular}




unknown
unknown
Yongzheng Sitting in the Pavilion
Yongzheng Indulged in Pleasures_Reading
by the Fire
Yongzheng Indulged in Pleasures_Becoming

an Immortal

Tang

1

Qing

2

Qing

unknown

unknown

Yongzheng Indulged in Pleasures_Lama

Dress

Qing

Yongzheng Indulged in Pleasures_Taoist

unknown

Costume

Qing

unknown

Chatting with Taoist

Qing

Yongzheng is reading,wearing the Dragon

unknown

Robe

Qing

unknown

Yongzheng is writing,wearing casual clothes

Qing

unknown

Qianlong is writing

Qing

2

unknown

Xuande Emperor Hunting in the Wild

Ming

Lang Shining, Shen

Yuan, Zhou Kun,

Zhou/Guanpeng,

Ding

Shining, Lang/Yuan,

Shen/Kun,

Zhou/Guanpeng,

Ding 
Shining, Lang/Yuan,

Shen/Kun,

Zhou/Guanpeng,

Ding

Shining, Lang/Yuan,

Shen/Kun,

Zhou/Guanpeng,

Qianlong Shot a Wolf _ Qing

Ding

unknown

Qianlong and his wife shot a deer

Qing

Qianlong in the prime of life,wearing the

unknown

Dragon Robe

Qing

unknown

Yongzheng in the Dragon Robe

Qing

Xuande Emperor Indulged in

unknown

Ming

Pleasures_Pitch-pot

unknown

Tongzhi Enjoys Pleasured in the Garden

Qing

Daoguang Stayed in the Autumn Courtyard

unknown

Happily

Qing

unknown

Watching butterflies in the summer

Qing

unknown

Viewing Bamboo Leaning on the door

Qing

Danxu, Fei

Twelve girls in Dream of the Red

Mansion_Li Wan

Qing

Danxu, Fei

Twelve girls in Dream of the Red

Mansion_Jia Yingchun

Qing

Danxu, Fei

Twelve girls in Dream of the Red

Mansion_Jia Yuanchun

Qing 
Danxu, Fei

unknown

Danxu, Fei

unknown

Tingbiao, Jin

Bingzhen, Jiao

Bingzhen, Jiao

Bingzhen, Jiao

Bingzhen, Jiao

Bingzhen, Jiao

Bingzhen, Jiao

Bingzhen, Jiao

unknown

unknown

unknown

unknown

Hanchen, $\mathrm{Su}$

Hanchen, $\mathrm{Su}$

Kazunobu, Kano

Tingbiao, Jin

unknown

Hanchen, $\mathrm{Su}$
Twelve girls in Dream of the Red

Mansion_Lin Daiyu

Qing

Empress of Filial Piety and Chastity

Qing

Twelve girls in Dream of the Red

Mansion_Miao Yu

Qing

Women in the Garden

Qing

3

A woman is wearing flowers in her hair

Qing

3

Picking Rattan to Make Clothes for Parents

Qing

3

Dressing Plain Clothes

Qing

3

Admonishing the Clan

Qing

3

Planting Crops in the Palace

Qing

3

Governing the Country Wisely

Qing

3

Filial Piety to the Elders

Qing

3

Rearing Silkworm in the Palace

Qing

Reading and Meditating

Qing

3

Sitting beside the Chrysanthemum

Qing

3

Watching snow next to hearth

Qing

3

Children playing in the courtyard in summer Yuan

4

Children playing in the courtyard in autumn Song

4

Children playing in winter

Song

4

The Game of Chicken

Qing

4

Children playing games with grass

Qing

4

Children playing on a platform

Ming

4

Northern

Children Playing in a Palace Garden 


\begin{tabular}{|c|c|c|}
\hline Xuan, Qian & Children playing beside a palm tree & Yuan \\
\hline unknown & Picking herbal medcine & Qing \\
\hline Hongshou, Chen & Children praying to Buddha & Ming \\
\hline unknown & Playing around the rockery & Song \\
\hline Hanchen, $\mathrm{Su}$ & Children playing in the courtyard in autumn & Song \\
\hline unknown & Children playing in the garden & Ming \\
\hline Hanchen, $\mathrm{Su}$ & Children romping in the yard & Song \\
\hline unknown & Palace Children Playing & Song \\
\hline $\mathrm{Pu}$, Wang & $\begin{array}{l}\text { Children playing in the garden with their } \\
\text { mother }\end{array}$ & Qing \\
\hline unknown & Children playing in autumn scenery & Yuan \\
\hline Hanchen, Su & The Knickknack Peddler & $\begin{array}{l}\text { Northern } \\
\text { Song }\end{array}$ \\
\hline unknown & Naughty Children fighting in the courtyard & Song \\
\hline unknown & Children at Play & Song \\
\hline Xinzhong, Lu & The Portrait of 16 Rohan & Song \\
\hline Shengwen, Zhang & Buddhism Figure Paintings & Song \\
\hline Shengwen, Zhang & Buddhism Figure Paintings & Song \\
\hline Shengwen, Zhang & Buddhism Figure Paintings & Song \\
\hline Shengwen, Zhang & Buddhism Figure Paintings & Song \\
\hline unknown & The Portrait of Rohan & Song \\
\hline $\mathrm{Xu}$, Song & Rohan Album & Ming \\
\hline Xiu, Guan & Kan-akavatsa & Wu Dai \\
\hline $\mathrm{Xu}$, Song & Rohan Album & Ming \\
\hline Yunpeng, Ding & The Portrait of Rohan & Ming \\
\hline
\end{tabular}




\begin{tabular}{|c|c|c|c|}
\hline Yunpeng, Ding & The Portrait of Rohan & Ming & 5 \\
\hline Yunpeng, Ding & The Portrait of Rohan & Ming & 5 \\
\hline Tingbiao, Jin & The Portrait of Rohan & Qing & 5 \\
\hline Nong, Jin & A Rohan is reading the Buddhist Scripture & Qing & 5 \\
\hline unknown & The Portrait of Rohan & Ming & 5 \\
\hline Bin, $\mathrm{Wu}$ & The Portrait of Rohan & Ming & 5 \\
\hline Songnian, Liu & The Portrait of Rohan & Song & 5 \\
\hline Xinzhong, Lu & The Portrait of 16 Rohan & Song & 5 \\
\hline Xinzhong, Lu & The Portrait of 16 Rohan & Song & 5 \\
\hline Xinzhong, Lu & The Portrait of 16 Rohan & Song & 5 \\
\hline \multicolumn{4}{|c|}{ Discrimination Session } \\
\hline unknown & Bodhisattva leads the dead to paradise & Wu Dai & 1 \\
\hline unknown & Illustration of the Buddhist Scripture & Wu Dai & 1 \\
\hline Bin, $\mathrm{Wu}$ & The Portrait of Samantabhadra & Ming & 1 \\
\hline Daqian, Zhang & Water moon kuan-yin & CHRP & 1 \\
\hline Norifusa & Bodhisattva-Ragaraja & Qing & 1 \\
\hline unknown & The Tang-ka & Yuan & 1 \\
\hline unknown & Water moon kuan-yin & Wu Dai & 1 \\
\hline Yunpeng, Ding & Five kinds of looks of Guanyin & Ming & 1 \\
\hline Guanpeng, Ding & The Portrait of Avalokitesvara & Qing & 1 \\
\hline unknown & The Portrait of Bodhisattva Manjusri & Ming & 1 \\
\hline unknown & Samantabhadra & Tang & 1 \\
\hline unknown & Bodhisattva leads the dead to paradise & Tang & 1 \\
\hline Liying, Jin & The Portrait of Avalokitesvara & Qing & 1 \\
\hline Daqian, Zhang & Avalokitesvara in white dress & CHRP & 1 \\
\hline
\end{tabular}


Daqian, Zhang

The Portrait of Avalokitesvara

CHRP

1

unknown

Shakya Muni and Bodhisattva

Yuan

1

unknown

Nyoirin Kannon sitting a top island paradise

Fudaraku

Yuan

1

unknown

The Bodhisattva Avalokitesvara

Qing

1

Xigui, $\mathrm{Hu}$

The Portrait of Avalokitesvara

Qing

1

unknown

Lotus Kwun Yin

Ming

1

Yongzheng Indulged in

unknown

Pleasures_Shouldering a Cattail Hassock

Qing

Shining, Lang/Yuan,

Shen/Kun,

Zhou/Guanpeng,

Qianlong Hunted and Had Picnic

Qing

Ding

Shining, Lang/Yuan,

Shen/Kun,

Zhou/Guanpeng,

Qianlong Shot a Wild Duck

Qing

2

Ding

Shining, Lang/Yuan,

Shen/Kun,

Zhou/Guanpeng,

Qianlong Shot a Bear

Qing

Ding

unknown

Qianlong in his later years, wearing the

Dragon Robe

Qing

Xuande Emperor Indulged in

unknown

Pleasures_Shooting

Ming 
unknown

unknown

unknown

unknown

unknown

unknown

unknown

unknown

unknown

unknown

unknown

unknown

unknown

unknown

unknown

Danxu, Fei
Xuande Emperor Indulged in

Pleasures_Football

Ming

Xuande Emperor Indulged in

Pleasures_Polo

Xuande Emperor Indulged in

Pleasures_Chui Wan

Ming

Qianlong Appreciated Antiques

Qing

Yongzheng Indulged in Pleasures_Reading

by the Fire

Qing

Yongzheng Indulged in Pleasures_Taoist

\section{Costume}

Qing

Yongzheng is writing,wearing casual clothes Qing

Qianlong is writing

Qing

Xuande Emperor Hunting in the Wild Ming

Qianlong and his wife shot a deer

Qing

2

Yongzheng in the Dragon Robe

Qing

Xuande Emperor Indulged in

Pleasures_Pitch-pot

Ming

Tongzhi Enjoys Pleasured in the Garden

Qing

Daoguang Stayed in the Autumn Courtyard

\section{Happily}

Qing

Holding a Ruyi in Hand

Qing

3

Twelve girls in Dream of the Red

Mansion_Xue Baochai
Qing 
Danxu, Fei

Danxu, Fei

unknown

Danxu, Fei

Danxu, Fei

Danxu, Fei

unknown

unknown

unknown

Danxu, Fei

unknown

Bingzhen, Jiao

Bingzhen, Jiao

Bingzhen, Jiao

Bingzhen, Jiao

Bingzhen, Jiao

unknown

unknown

Hanchen, Su
Twelve girls in Dream of the Red

Mansion_Shi Xiangyun

Qing

Twelve girls in Dream of the Red

Mansion_Jia Tanchun

Qing

One of the Imperial Concubine of Qianlong

Qing

Twelve girls in Dream of the Red

Mansion_Jia Xichun

Qing

Twelve girls in Dream of the Red

Mansion_Wang Xifeng

Qing

Twelve girls in Dream of the Red

Mansion_Qin Keqing

Qing 3

Tasting Tea under a Tung Tree

Qing

Sewing clothes in candlelight

Qing

Viewing Bamboo Leaning on the door

Qing

Twelve girls in Dream of the Red

Mansion_Jia Yuanchun

Qing

Empress of Filial Piety and Chastity

Qing

Picking Rattan to Make Clothes for Parents

Qing

Admonishing the Clan

Qing

Governing the Country Wisely

Qing

3

Filial Piety to the Elders

Qing

3

Rearing Silkworm in the Palace

Qing 3

Reading and Meditating

Qing

Watching snow next to hearth

Qing

Palace children playing in the garden

Song 
Hanchen, Su
Gan, Han
Hanchen, Su
Tingbiao, Jin

Xuan, Qian

unknown

Hanchen, $\mathrm{Su}$

unknown

Hanchen, $\mathrm{Su}$

Hanchen, $\mathrm{Su}$

Tingbiao, Jin

unknown

Hanchen, $\mathrm{Su}$

unknown

unknown

Hanchen, $\mathrm{Su}$

unknown

unknown

unknown

Xinzhong, Lu

Xinzhong, Lu
Children playing in the courtyard in autumn Song

Tang

Song

Qing

Yuan

4

willow

Royal children playing in winter

Yuan

4

Northern

Winter Play

Children Cooking Pao-tzu

One Hundred Children in the Long Spring

Children playing in the courtyard in autumn

Children playing games with grass

Children playing on a platform

Children Playing in a Palace Garden

Picking herbal medcine

Playing around the rockery

Children playing in the courtyard in autumn

Children playing in the garden

Children playing in autumn scenery

Naughty Children fighting in the courtyard

The Portrait of 16 Rohan

Song

Song

4

4

4

4

4

Song

Yuan

4

Northern

Song

Song

4

Qing

4

Ming

4

Northern

Song

Qing

Song 4

Song 4

Ming 4

Yuan 4

Song 4

The Portrait of 16 Rohan
4

4

4

4

4




$\begin{array}{llll}\text { Shengwen, Zhang } & \text { Buddhism Figure Paintings } & \text { Song } & 5 \\ \text { Xu, Song } & \text { Rohan Album } & \text { Ming } & 5 \\ \text { Xu, Song } & \text { Rohan Album } & \text { Ming } & 5 \\ \text { Yunpeng, Ding } & \text { The Portrait of Rohan } & \text { Ming } & 5 \\ \text { Bin, Wu } & \text { The Portrait of } 18 \text { Rohan } & \text { Ming } \\ \text { Songnian, Liu } & \text { The Portrait of Rohan } & \text { Song } \\ \text { Guandao, Liu } & \text { Protectors Gather for Zen } & \text { Yuan } \\ \text { Songnian, Liu } & \text { The Portrait of Rohan } & \text { Song } \\ \text { Xinzhong, Lu } & \text { The Portrait of } 16 \text { Rohan } & \text { Song } \\ \text { Shengwen, Zhang } & \text { Buddhism Figure Paintings } & \text { Song } \\ \text { Shengwen, Zhang } & \text { Buddhism Figure Paintings } & \text { Song } \\ \text { Shengwen, Zhang } & \text { Buddhism Figure Paintings } & \text { Song } & 5 \\ \text { Xu, Song } & \text { Rohan Album } & \text { Ming } & 5 \\ \text { Xu, Song } & \text { Rohan Album } & \text { Ming } & 5 \\ \text { Yunpeng, Ding } & \text { The Portrait of Rohan } & \text { Ming } & 5 \\ \text { Nong, Jin } & \text { The Portrait of Rohan } & 5\end{array}$

Note. In fourth column is shown motif category $(1=$ Bodhisattva, $2=$ Emperor, $3=$ Noble Woman, 4 = Palace Children, $5=$ Rohan . 